IZA DP No. 4457

The Dynamics of Social Assistance Benefit Receipt in Britain

Lorenzo Cappellari

Stephen P. Jenkins

September 2009 


\title{
The Dynamics of Social Assistance Benefit Receipt in Britain
}

\author{
Lorenzo Cappellari \\ Università Cattolica, Milano, \\ ISER, University of Essex and IZA \\ Stephen P. Jenkins \\ ISER, University of Essex \\ and IZA
}

\section{Discussion Paper No. 4457 \\ September 2009}

\author{
IZA \\ P.O. Box 7240 \\ 53072 Bonn \\ Germany \\ Phone: +49-228-3894-0 \\ Fax: +49-228-3894-180 \\ E-mail: iza@iza.org
}

\begin{abstract}
Any opinions expressed here are those of the author(s) and not those of IZA. Research published in this series may include views on policy, but the institute itself takes no institutional policy positions.

The Institute for the Study of Labor (IZA) in Bonn is a local and virtual international research center and a place of communication between science, politics and business. IZA is an independent nonprofit organization supported by Deutsche Post Foundation. The center is associated with the University of Bonn and offers a stimulating research environment through its international network, workshops and conferences, data service, project support, research visits and doctoral program. IZA engages in (i) original and internationally competitive research in all fields of labor economics, (ii) development of policy concepts, and (iii) dissemination of research results and concepts to the interested public.
\end{abstract}

IZA Discussion Papers often represent preliminary work and are circulated to encourage discussion. Citation of such a paper should account for its provisional character. A revised version may be available directly from the author. 
IZA Discussion Paper No. 4457

September 2009

\section{ABSTRACT \\ The Dynamics of Social Assistance Benefit Receipt in Britain}

We analyze the dynamics of social assistance benefit (SA) receipt among working-age adults in Britain between 1991 and 2005. The decline in the annual SA receipt rate was driven by a decline in the SA entry rate, rather than by the SA exit rate (which actually declined too). We examine the determinants of these trends using a multivariate dynamic random effects probit model of SA entry and exit probabilities applied to British Household Panel Survey data. The model estimates and accompanying counterfactual simulations highlight the importance of two factors - the decline in the unemployment rate over the period, and other changes in the socioeconomic environment including two reforms to the income maintenance system in the 1990s. The results also reveal a substantial heterogeneity in SA annual transition rates.

JEL Classification: $\quad$ 138, C33, C35

Keywords: benefits, income dynamics, social assistance, welfare, dynamic random effects probit

Corresponding author:

Stephen P. Jenkins

Institute for Social and Economic Research

University of Essex

Wivenhoe Park

Colchester CO4 3SQ

United Kingdom

E-mail: stephenj@essex.ac.uk

\footnotetext{
* This is a substantially revised version of a report commissioned by the OECD under contract JA00045191 (Cappellari and Jenkins 2008a). For helpful comments and suggestions at various stages, we thank Thomas Andrén, Martin Biewen, Ken Couch, Jürgen Hansen, Herwig Immervoll, Alfonso Miranda, Chris Orme, Lucinda Platt, Mark Stewart, and audiences at a Motu Public Policy Seminar (Wellington), National Institute of Economic and Social Research (London), Social Policy Research Centre (Sydney), Welsh Economics Colloquium, Italian Association of Labour Economists Annual Congress, European Society for Population Economics Annual Congress, and the Joint OECD/University of Maryland International Conference on "Measuring Poverty, Income Inequality, and Social Exclusion: Lessons from Europe".
} 


\section{INTRODUCTION}

For at least two decades, “welfare to work” ideas have strongly influenced social policy thinking on both sides of the Atlantic and in English-speaking OECD nations more generally. There has been substantial interest in reorienting the design of systems of cash transfers for poor working-age families away from schemes involving passive receipt of benefits ("welfare”) towards schemes in which individuals are more actively involved in meeting minimum income requirements, by increasing their labor market participation (“work”). In the USA, this reorientation is illustrated by the abolition of the Aid for Families with Dependent Children program by the 1996 Personal Responsibility and Work Opportunity Reconciliation Act and introduction of the Temporary Assistance for Needy Families program with time limited benefit payments. The Earned Income Tax Credit program supporting low income working families was expanded during the 1980s and 1990s, and is a major anti-poverty policy.

Britain’s Labour Government, elected in 1997, was strongly influenced by the US reforms. It is responsible for substantial extensions to the provision and generosity of in-work benefits through the Working Families Tax Credit (WFTC) program introduced in 1999 and modified and extended in 2003. Major social assistance benefit programs for working age families remain in place, however, though with some modifications in the mid-1990s that tightened eligibility requirements for unemployed people of working age.

This background raises questions such as: How much did dependence on social assistance benefits decline over the last two decades in Britain? To what extent were policy reforms responsible for observed trends and what was the role played by other factors such as labor market tightness? This paper documents what happened to social assistance benefit receipt dynamics in Britain over the period 1991-2005 and explains trends using an econometric model fitted to household panel data.

To set the scene, look at Figure 1 which shows trends in receipt of social assistance benefit (SA) receipt in Britain. (Definitions and data are explained in more detail later.) Apart from the rise in receipt at the beginning of the 1990s when Britain went into recession, the percentage of working age adults in receipt of SA halved, falling from a peak of around 12 percent in 1993 to around 6 percent in 2005. If the definition of SA is widened to include housing benefits, the proportion in receipt each year is consistently 2-3 percent higher, but follows a similar downward trend. Two leading explanations for these trends are the reforms to the benefit system intending to "make work pay" and changes in labor market tightness. 
Figure 1 shows the substantial increase over the period in receipt of in-work cash assistance ('tax credits'). The proportion of working-age adults in receipt was consistently about 2-3 percent during the 1990s, until the introduction of WFTC in October 1999 after which the proportion in receipt rose dramatically to almost 7 percent in 2002. The receipt rate then rose again significantly with the extension of eligibility in 2003. Observe that the turning points in the SA receipt rate series do not correspond closely with the turning points in the series for tax credit receipt, suggesting that in-work benefit reforms were not a major driver of the former. By contrast, note the relatively close correspondence between the trends in the unemployment rate and in the SA receipt rate. These and other explanations are examined in greater detail later in the paper.

$<$ Figure 1 near here $>$

Since changes in SA receipt rate from year to year reflect the combination of changes in annual rates of entry to or exit from receipt (which are processes with different determinants), we analyze entry and exit rates. Figure 2 shows the trends in these SA transition rates over the period 1991-2005. The entry rate fell from above 4 percent in 1993 to below 2 percent in 2005. The exit rate fell from around 40 percent to nearly 25 percent (the greater variability in the rate at the end of the period may simply reflect small sample sizes).

$<$ Figure 2 near here $>$

We conclude that the secular decline in annual (cross-sectional) SA receipt rates was driven primarily by a decline in entry rates: the fall in the entry rate was sufficiently large that it offset the decline in the exit rate over the same period (which would increase receipt rates, other things being equal). This conclusion follows directly from the stock-flow identity that links the proportion receiving SA in year $t$ to entry and exit rates. ${ }^{1}$ The importance for trends in cross-sectional receipt of changes in the entry rate rather than the exit rate echo findings reported for the USA by Grogger (2004) and Haider and Klerman (2005).

To investigate the determinants of these trends, we propose a multivariate dynamic random effects probit model of individuals' annual SA entry and exit probabilities and fit it to data from waves 1-15 of the British Household Panel Survey (BHPS). Estimates of the model and simulated exit and entry rates derived from them are used to assess the determinants of the observed trends. The results highlight the importance of both the decline in the unemployment rate and other secular changes in the socioeconomic environment

\footnotetext{
${ }^{1}$ The proportion receiving SA in year $t, p_{t}$, is given by: $p_{t}=\left(1-x_{t}\right) p_{t-1}+e_{t}\left(1-p_{t-1}\right)$, where $x_{t}$ is the exit rate and $e_{t}$ is the entry rate at $t$.
} 
including two reforms to the social security benefit system. The results also point to substantial individual heterogeneity in SA transition rates.

In the next section, we explain the nature of benefit system in Britain today, referring to both SA and in-work benefits, and the major changes that occurred over the period 19912005. In subsequent sections, we introduce the British Household Panel Survey (BHPS) data used in the analysis, and then present the statistical model, estimates and results.

The focus throughout is on individuals of working age. More specifically, we consider only individuals below the age of 60. (The state retirement pension age in Britain is 60 for woman and 65 for men.) To avoid complications associated with education and training, we also exclude individuals aged less than 25 , or individuals in families in which there are any adults of working age who are full-time students.

This paper is a substantially revised version of a longer report (Cappellari and Jenkins 2008a) to which we refer readers for additional explanations and detail. For this paper, we have revised aspects of the specification of the dynamic random effects probit model, and present counterfactual simulations to analyze the various determinants of trends.

\section{BENEFITS AND TAX CREDITS IN BRITAIN}

Social assistance benefits are income-tested "safety net” cash benefits, sometimes called "welfare benefits". They are paid to bring incomes up to some minimum income level - they refer to income maintenance. By contrast, social insurance benefits refer to income replacement - payments made in response to the occurrence of particular risky events such as sickness or unemployment and for which an appropriate record of social insurance contributions exists. ${ }^{2}$ See the OECD Glossary of statistical terms used in the National Accounts at http://stats.oecd.org/glossary/detail.asp?ID=2478.

\footnotetext{
${ }^{2}$ There are also benefits for individuals who are ill or injured that are not discussed here: Statutory Sick Pay for employees, Employment and Support Allowance (replacing Incapacity Benefit since October 2008) for those unable to work because of illness or disability and with a suitable national insurance contributions record, Industrial Injuries Disablement Benefit for those ill or disabled because of an accident or event that happened at work or in connection with work. For an overview of the current British system of cash benefits and tax credits for working and non-working families, see http://www.direct.gov.uk/en/MoneyTaxAndBenefits/BenefitsTaxCreditsAndOtherSupport/index.htm. For crossnational comparisons of income maintenance systems, see Immerwoll (2009), Midgley (2008), and Walker (2005).
} 


\section{The Current System of Benefits and Tax Credits}

The principal social assistance benefits in Britain for people of working age, according to these definitions, are those shown in Table 1. Income Support (IS) and income-based Job Seekers Allowance (JSA) differ from Housing Benefit (HB) and Council Tax Benefit (CTB) because receipt depends on employment status. Put differently, receipt of HB and CTB depends on income (and some other conditions), but not on employment or job-search status. As Figure 1 shows, the SA receipt rates according to both the narrower and broader definitions move in tandem over time. The populations receiving IS and JSA on the one hand, and HB and CTB on the other hand, overlap substantially, and so the choice of whether to include housing benefits in the definition of social assistance benefits is of little practical importance in the current context. In the analysis presented below, we do not include housing benefits (HB and CTB) in our definition of SA.

$<$ Table 1 near here $>$

Alongside these benefits for non-working families, there is extensive cash support available for low income working families, currently through the Working Tax Credit program. (It plays a similar role to the Earned Income Tax Credit in the USA.) The eligibility conditions relate to having an income below a specified minimum level, and at least one family member in "full-time work" defined to mean working at least 16 hours per week.

\section{Changes, 1991-2005}

Over the period under analysis, the system of benefits and tax credits in Britain changed substantially. The main reforms are summarized, by year of introduction, in Table 2. Prior to 1996, a non-working family could be receiving Income Support (social assistance), Unemployment Benefit (UB, social insurance), or both. In October 1996, cash benefits for unemployed jobseekers were unified under the Job Seekers Allowance (JSA) program, with a distinction made between “income-based” JSA corresponding to the former Income Support and "contribution-based" JSA corresponding to the former UB, which was a flat-rate nonmeans-tested social insurance benefit paid to unemployed individuals with a satisfactory National Insurance contribution record. JSA also incorporated more stringent job search requirements for those assessed as available for work. Unemployed individuals with an incomplete national insurance contribution record and a sufficiently low income were also eligible to claim contribution-based JSA on a means-tested basis. Because UB payments were relatively low, most recipients' families were also eligible for IS, and it remains the case 
today that most JSA recipients receive income-based benefits. ${ }^{3}$ Official statistics on JSA numbers no longer distinguish between contribution-based and income-based JSA, and it is also difficult to identify them separately in household surveys. For this reason, we include both types of JSA in our definition of SA: see below.

$<$ Table 2 near here $>$

The other main changes were introduced by the new Labour government that was elected in May 1997. The most significant reform was the replacement of the existing inwork benefits program, Family Credit, by the Working Families Tax Credit (WFTC) program modeled more closely on the US EITC. Aiming to "make work pay", WFTC had more generous payments and extended eligibility notably by lowering the number of work hours required for qualification. Take-up was substantial, as Figure 1 illustrates. In 2003, the child allowance elements of WFTC were spun out into the Child Tax Credit program, which aimed to unify child support payments across the income maintenance system more generally. The WFTC component supplementing earnings became Working Tax Credit, and eligibility was extended to single people and to families without children. This gave another fillip to the proportion of working-age adults receiving tax credits: see Figure 1.

Among other policy reforms introduced by the Labour government to make work pay was a national minimum wage rate per hour. And, as part of its aim to reduce child poverty, there was an increase in support for families with children through increases in Child Benefit (a universal non-income-tested benefit paid per child) and in the child allowance element of other benefits. ${ }^{4}$

Brewer and Shephard's (2004) summary assessment, focusing on families with dependent children, is that “[e]xamining outcomes of Labour's ultimate objectives would lead one to conclude that the make work pay policies have been a success. ... Academic studies agree that government policies were partially responsible for these changes, at least among lone parents.” (2004, p. vii.) ${ }^{5}$

\footnotetext{
${ }^{3}$ According to the latest administrative statistics, at 1 August 2004, there were 737,000 JSA recipients in total, of whom 18 percent $(136,000)$ received only contribution-based JSA and 82 percent $(601,000)$ received incomebased JSA, including 12,000 with underlying entitlement to contribution-based benefit. See http://www.dwp.gov.uk/asd/asd1/stats_summary/Stats_Summary_dec2004_final.pdf.

${ }^{4}$ There were also a number of active labor market programs for specific groups, the New Deals for unemployed young people and for lone parents, providing individualized help to improve job readiness and job search. Because of their targeted focus, and since they do not directly affect incomes, they are less relevant in the current context.

${ }^{5}$ For an overview of the impact of WFTC on labor supply and other outcomes, see the Economic Journal Features issue on 'In-work benefit reform in a cross-national perspective' (Brewer et al. 2009).Earlier research focusing on labor supply effects includes Blundell (2001), Blundell and Hoynes (2004), Brewer et al. (2006), Francesconi and van der Klaauw (2007), and Gregg et al. (2009).
} 
To the extent that policies making work pay are successful, we would expect them to be accompanied by corresponding reductions in SA receipt, and for the turning points and inflections in SA receipt trend lines to correspond with the major changes in tax credits (1999 and 2003). Similarly, we would expect the tightening of job search requirements for unemployed people accompanying the introduction of JSA in 1996 to lead to a decline in SA receipt, other things equal. Analysis of administrative record data by Petrongolo (2007) of men aged 16-64 suggests that tighter job search requirements were successful in moving individuals off unemployment benefits. Manning (2009) derives the same conclusion using Labour Force Survey data. ${ }^{6}$

\section{DATA: THE BRITISH HOUSEHOLD PANEL SURVEY}

We track SA receipt among working age adults using BHPS data from survey years 1991 to 2005. ${ }^{7}$ The first wave of the BHPS is a nationally representative probability sample of the private household population, with interviews in the Autumn of 1991. The achieved sample consists of more than 10,000 individuals in some 5000 households, who have been reinterviewed annually. Individuals in split-off families are followed, as in other household panels such as the US Panel Study of Income Dynamics or the German Socio-Economic Panel. For full documentation of the BHPS, see http://www.iser.essex.ac.uk/survey/bhps.

We define an individual to be in receipt of SA if any individual in his or her family is receiving social assistance benefits at the time of the BHPS interview. In Britain, assessment of benefit eligibility is based on the income of the nuclear family, the so-called "benefit unit", which is a single person or a couple living together with or without dependent children. (A dependent child is aged less than 16 years, or more than 16 years but under 19 years and unmarried, in full-time non-advanced education and living with his/her parents.) It is not legal marital status that distinguishes a "couple” from two single adults; it is living arrangements (cohabiting unions are treated like legal marriages). In the sample of SA recipients we analyze, only one quarter are lone parents, 54 percent live with a partner (37

\footnotetext{
${ }^{6}$ At the same time, the reform did not increase the job-finding rate unambiguously, because some recipients moved instead to other benefits such as incapacity benefits (Manning 2009; Petrongolo 2007).

${ }^{7}$ We use respondents to the original ('Essex') sample only. Respondents from the extension samples for Scotland, Wales and Northern Ireland incorporated in the BHPS at the end of the 1990s are not used. Taking account of the differential sample inclusion probabilities would be a large task, beyond the scope of this project, and the number of observations in the original 1991 sample is relatively large in any case (see below).
} 
percent have a partner and children), and 21 percent are childless single adults. ${ }^{8}$ We track individuals over time, not families, since families and households cannot be followed over time as a unit in any consistent manner. Families and households change their composition over time as individuals arrive (e.g. via partnership formation) or depart (e.g. via partnership dissolution). These types of change are common (Jenkins 2000).

We define SA to include IS and either UB or JSA (of either type). This is a matter of practical necessity: it is the only definition of SA that can be measured consistently over time using the BHPS (and most other surveys). As mentioned earlier, it is difficult to reliably distinguish between receipt of contribution-based JSA and income-based JSA. Indeed, since JSA's introduction in 1996, the BHPS interview has not asked respondents receiving JSA to distinguish between the two types for precisely this reason. See Cappellari and Jenkins (2008a) for further discussion.

Our definition of SA receipt for a given year $t$ refers to receipt at the time of the BHPS interview in survey year $t$ (typically September or October) - this is the definition used for Figure 1. The entry rate refers to the proportion of individuals not receiving SA the year $t-1$ interview that are receiving SA at the year $t$ interview and the exit rate refers to the proportion of individuals receiving SA at the year $t-1$ interview that are not receiving SA at the year $t$ interview. Thus, the dynamics of SA receipt analyzed in this paper refer to transitions to and from receipt between successive annual interviews.

An alternative approach to receipt dynamics is to take a spell-based approach, where spells are defined in terms of consecutive "benefit years" or, where data are available, consecutive sub-annual periods such as "months". ${ }^{9}$ For the USA, the benefit year approach has been applied in studies using PSID data from the pioneering analysis of AFDC benefit receipt by Bane and Ellwood $(1983,1994)$ onwards. The latter approach is commonly applied in studies based on the Survey of Income and Program Participation or administrative record data.

By focusing on transitions between annual interviews, we play to the BHPS's strengths. Wishing to minimize measurement error and respondent burden, most BHPS effort is devoted to collecting information about the various income sources received at the time of the interview and the corresponding amounts. To be sure, at each interview the survey also asks about receipt of each of a large number of cash benefits for each month between the

\footnotetext{
${ }^{8}$ We use the British term "lone parent" rather than "single mother" because the majority of lone parenthood spells in Britain arise from the ending of a partnership rather by a birth to a single-never-married woman. ${ }^{9}$ A "benefit year" refers to receipt at least once during that year.
} 
interview month and the September of the year prior to the current survey year using the respondent's retrospective recall. There are, however, substantial complications arising in the creation of consistent monthly histories of SA receipt. Not only are there "seam” problems to deal with (an implausible number of transitions at the seam where successive histories overlap and have to be spliced together), but there are also issues arising from the familybased measure of receipt since histories are required for all the individuals who were in each person's family month by month. See Cappellari and Jenkins (2008a) for further discussion. Addressing these issues is a major and important task, but beyond the scope of this paper. We therefore remind readers that our analysis focuses on SA transitions between one year and the next, and not on spells of receipt.

With fifteen waves of BHPS data, our analysis data set contains a maximum of 15 observations per individual on SA receipt and other variables. At least two consecutive waves of data are required to estimate transition rates and any multivariate model of dynamics. We track individuals from when they are first observed as BHPS respondents until the first wave at which they drop out of the panel, either completely non-responding or with item nonresponse of sufficient degree that the individual's data cannot be used for estimation. If individuals rejoin the panel at some later wave, leading to gaps in benefit receipt sequences, we exclude them because taking account of intermittent participation complicates modeling substantially. Thus, we focus on what is known as the 'absorbing attrition' case. The sample used for the empirical analysis is restricted to individuals of working age and not in full-time education (see earlier), and without missing data for some important explanatory variables. The basic estimation sample is an unbalanced panel of 75,988 person-wave observations for 9,036 adults. The majority (56 percent) of the sequences start at wave 1 , but there are sequences that begin at each subsequent wave as well (roughly 200-300 adults each year). See Cappellari and Jenkins (2008a) for further details concerning sample selection, and demonstration that conclusions are robust to the use of a balanced rather than an unbalanced panel.

\section{A DYNAMIC RANDOM EFFECTS PROBIT MODEL OF TRANSITION PROBABILITIES}

Our data consist of a temporally ordered sequence of ones (representing SA receipt at a particular interview) or zeros (representing non-receipt), for every adult included in the 
analysis sample. To analyze these data, we propose use of panel data methods for binary sequences, specifically a version of the dynamic random effects probit model popularized by Heckman (1981a) which also accounts for unobserved individual heterogeneity. Dynamic random effects probit models have been used to analyze social assistance dynamics in Sweden and Canada by Andrén (2007), Hansen and Lofstrom (2006), and Hansen et al. (2006). One US application is by Chay and Hyslop (2000). Our model differs from those cited because we allow the same set of covariates to affect exit and entry rates but with potential different impacts. ${ }^{10}$ More generally, we know of no previous study that has used dynamic random effects probit models to analyze and simulate entry and exit rates in the way that we do.

\section{The Multivariate Statistical Model}

Let $p^{*}{ }_{i t}$ represent the latent probability of SA receipt in each year of the sequence of $T_{i}$ years for which an individual is observed in the analysis panel data, excluding the first year $(t=1)$, where

$$
p_{i t}^{*}=\gamma^{\prime} Z_{i t-1}+\lambda^{\prime} W_{i t-1} y_{i t-1}+\tau_{i}+\zeta_{i t} ; \quad t=2, \ldots, T_{i} .
$$

Each individual, $i=1, \ldots, N$, is observed to receive SA $\left(y_{i t}=1\right)$ in year $t$ if $p^{*}{ }_{i t}>0$, and not to receive it $\left(y_{i t}=0\right)$ otherwise. Observed individual heterogeneity is measured by the vector of variables represented by $Z_{i t-1}$ and $W_{i t-1}$ (each of which includes an intercept term). These variables are measured in the year at which the individual is at risk of making a transition (year $t-1$ ). As we show shortly, the interactions between the lagged dependent variable $\left(y_{i t-1}\right)$ and each element of $W_{i t-1}$ allow characteristics to affect entry and exit rates differently.

Unobserved heterogeneity is characterized by a fixed individual-specific component $\left(\tau_{i}\right)$ and a white noise error component $\left(\zeta_{i t}\right)$, where the error terms are assumed to be uncorrelated with each other and with each element of $Z_{i t}$. The errors are each assumed to have a mean of zero and be normally distributed, with the variance of $\zeta_{i t}$ normalized to be one, and variance of $\tau_{i}$ estimated from the data. In order to relax the assumption that the unobserved individual-specific components are uncorrelated with the observed explanatory variables, we follow Mundlak (1978) and Chamberlain (1984), and many researchers since, in allowing for correlations between $u_{i}$ and $Z_{i t}$ by supposing that

\footnotetext{
${ }^{10}$ Ribar's (2005) endogenous switching model of AFDC transitions shares this feature, but models unobserved heterogeneity differently. On endogenous switching models of transitions, see also Cappellari and Jenkins $(2004,2008 b)$.
} 


$$
\tau_{i}=\xi^{\prime} \bar{Z}_{i}+u_{i}
$$

where $u_{i}$ is distributed $N\left(0, \sigma_{u}{ }^{2}\right)$ and is assumed independent of $Z_{i t}$ and $\zeta_{i t}$ for all persons and time periods. The $\bar{Z}_{i}$ may be defined in several ways - we follow the common practice of defining them as the longitudinal average for each individual of each characteristic within the vector $Z_{i t}$ (with the exception of intrinsically time-varying variables like age). Intuitively, differences in longitudinally-averaged characteristics are informative about underlying individual-specific characteristics, so that the unobserved individual differences that are left $\left(u_{i}\right)$ may be more plausibly supposed to be independent of observed characteristics. For brevity in notation, we subsume the longitudinally-averaged variables into the vector $Z_{i t}$ henceforth.

There is an issue for estimation concerning the 'initial conditions' of the sequence of observations for each individual - whether $y_{i 1}$ is independent of $u_{i}$. If receipt in the initial year is correlated with the time-invariant individual-specific effect, a correlation is induced between the error term and the lagged dependent variable in (1), leading to bias in parameter estimates.

We handle initial conditions using the conditional maximum likelihood estimator proposed by Wooldridge (2005). Rather than modeling the joint distribution of the sequence of binary receipt indicators from the initial one to the final one conditioning on the set of explanatory variables, Wooldridge showed that one may model the distribution of the binary receipt indicators from $t_{i}=2, \ldots, T_{i}$, conditioning on the set of explanatory variables and the binary receipt indicator for the initial year. Wooldridge proposed modeling the distribution of $\tau_{i}$ conditional on $y_{i 1}$ and either $Z_{i}=\left(Z_{i 1}, Z_{i 2}, \ldots, Z_{i T}\right)$, or $\bar{Z}_{i}$. His model for the individualspecific component (abstracting from $\bar{Z}_{i}$ already incorporated using the ChamberlainMundlak specification) can be written as:

$$
\tau_{i}=a_{0}+a_{1} y_{i 1}+u_{i}+\zeta_{i t}
$$

so that equation (1) becomes

$$
p^{*}{ }_{i t}=\gamma^{\prime} Z_{i t}+\lambda^{\prime} W_{i t-1} y_{i t-1}+\xi^{\prime} \bar{Z}_{i}+a_{0}+a_{1} y_{i 1}+u_{i}+\zeta_{i t} ; \quad t=2, \ldots, T_{i} .
$$

The Wooldridge estimator has the advantages that initial conditions do not have to be modeled and estimation can done using standard random-effects probit software. ${ }^{11}$

\footnotetext{
${ }^{11}$ In our earlier work (Cappellari and Jenkins 2008a), we showed that the Wooldridge estimator provided almost identical parameter estimates to the estimators of Heckman (1981) and Orme (2001) that also account for the initial conditions issue, for both balanced and unbalanced panels. We attribute this robustness to the long length of our panel. See also Arkay (2009) and Arulampalam and Stewart (2009). We focused on estimates based on
} 
The model outlined incorporates a relatively simple dynamic structure. It characterizes a first order Markov process: transition behavior does not depend on receipt history beyond the year before the current one. Higher order Markov models can be fitted as Chay and Hyslop (2001) and Stewart (2007) demonstrate, but we find that our model characterizes aggregate trends relatively well (see below). More flexible approaches to duration dependence can also be modeled using survival analysis methods applied to spell data. We eschew those methods because of the difficulties of deriving consistent monthly histories (see earlier), and because using the annual interview data to define spells would underestimate the prevalence of short spells. For spell length predictions from our first order Markov model ignoring the latter issue and employing a "steady state" assumption, see Cappellari and Jenkins (2008a).

\section{Model Implications for Entry and Exit Probabilities}

The dynamic random effects probit model characterizes transition probabilities for individuals of different types given appropriate conditioning on receipt status at $t-1$. The implied SA entry rate for non-recipients, $e_{i t}$, is:

$$
e_{i t} \equiv \operatorname{Pr}\left(y_{i t}=1 \mid y_{i t-1}=0, Z_{i t-1}, W_{i t-1}\right)=\Phi\left(\left(\gamma^{\prime} Z_{i t-1}\right) /(1-\rho)^{0.5}\right) .
$$

The implied SA persistence rate for recipients, $s_{i t}$, is

$$
s_{i t} \equiv \operatorname{Pr}\left(y_{i t}=1 \mid y_{i t-1}=1, Z_{i t-1}, W_{i t-1}\right)=\Phi\left(\left(\gamma^{\prime} Z_{i t-1}+\lambda^{\prime} W_{i t-1}\right) /(1-\rho)^{0.5}\right)
$$

and the SA exit rate for recipients, $x_{i t}$, is

$$
x_{i t} \equiv \operatorname{Pr}\left(y_{i t}=0 \mid y_{i t-1}=1, Z_{i t-1}, W_{i t-1}\right)=1-s_{i t}
$$

where $\rho=\sigma_{u}^{2} /\left(1+\sigma_{u}^{2}\right)$. The impact on the entry rate of a factor depends on the factor's coefficient in $\gamma$. For example, we would expect larger unemployment rates to be associated with a larger SA entry rate and a smaller exit rate (a larger persistence rate), other things being equal. In this case, the coefficient on the unemployment rate in $\gamma$ (call it $\gamma_{\text {unemp }}$ ) would be positive. For exit rates, ascertaining associations is not quite as straightforward. A negative association between the exit rate and the unemployment rate requires $\gamma_{\text {unemp }}+\lambda_{\text {unemp }}$ to be negative.

We simulate aggregate entry and exit rates for each year using (5) and (7) and our estimates of $\gamma, \lambda$ and $\sigma_{u}^{2}$ to derive predicted probabilities of entry and exit for each individual 
at risk of a transition that year, and then averaging the individual-specific probabilities across those at risk. Thus, the model characterizes of changes over time in aggregate entry and exit rates in terms of either changes over time in coefficients (including intercepts) when allowed to be time-varying, or changes over time in the distribution of characteristics among those at risk of exit or entry (such as an upgrading in educational qualifications). We assess the impact of specific factors on trends using counterfactual simulations corresponding to these two sources of change, asking what would have happened to entry and exit rates were a set of coefficients to have remained fixed at the value for a specific year, or were the distribution of a particular characteristic to have remained as in the distribution for a specific year.

\section{Explanatory variables}

Observed characteristics are summarized by sex and age, highest educational qualification, and health status. Age refers to whether the individual is aged 50 or more years: we expect older workers to have less work attachment, other things equal, and hence higher SA entry and lower SA exit rates. We distinguish four categories of educational qualification: none, low, high, and missing. "Low" refers to having passes in examinations taken at age 16 (CSE(s) and/or O-levels); "high” refers to having passes in examinations taken at age 18 (Alevel(s)) or higher qualifications such as a degree. Around one tenth of respondents have missing data on educational qualifications: these are mostly respondents for whom only a proxy interview was gained but sufficient information was derived about other characteristics from the proxy respondent so that the individual could be included in the sample. The missing qualifications indicator is better interpreted as a control for response propensity than as a measure of educational qualifications. Health status refers to whether the respondent stated that s/he had one of more of 13 health problems. ${ }^{12}$

The characteristics of each respondent's family are summarized by the number of dependent children, whether the age of the youngest child is less than five years, and by family type (single adult, couple, or lone parent). We also control whether the respondent lives in the London area (as the labor market is very different from elsewhere in the country), and housing tenure (whether the respondent lived in owner-occupied housing rather than

\footnotetext{
extensive set of variables included in $W_{i t-1}$.

${ }^{12}$ The problems refer to: (1) Problems or disability connected with: arms, legs, hands, feet, back, or neck (including arthritis and rheumatism); (2) Difficulty in seeing (other than needing glasses to read normal size print); (3) Difficulty in hearing; (4) Skin conditions/allergies; (5) Chest/breathing problems, asthma, bronchitis; (6) Heart/blood pressure or blood circulation problems; (7) Stomach/liver/kidneys; (8) Diabetes; (9) Anxiety, depression or bad nerves; (10) Alcohol or drug related problems; (11) Epilepsy; (12) Migraine or frequent headaches; (13) Other health problems.
} 
other tenures such as social housing or renting privately). We do not suggest that tenure itself necessarily has an impact; rather it is a marker for other factors including differences in wealth and assets and local area disadvantage.

The remainder of the explanatory variables relate to the factors cited earlier in the descriptions of trends in aggregate receipt and transition rates (Figures 1 and 2). We summarize time-varying labor market tightness in terms of the respondent's local area unemployment rate. By local area, we mean travel-to-work area (TTWA). ${ }^{13}$

The impacts of policy changes are monitored by allowing the intercept terms in $Z_{i t-1}$ and $W_{i t-1}$ to differ by survey year. We follow this strategy rather than including measures of (say) program generosity over time for two reasons. First, benefit rates in the UK are set nationally; there is no spatial variation across regions or states as in the USA or some European countries. Second, there have many program changes within the 1991-2005 period (Table 2), and so it is difficult to identify the impact of any specific policy reform. Our approach is therefore more descriptive than causal modeling: we expect that if the policies cited in Table 2 had an effect on SA entry and exit rates, they will be reflected in the timevarying intercepts, notably around 1996, 1999 and 2003. ${ }^{14}$

\section{Characteristics of At-Risk Groups, and Trends over Time}

Changes in the aggregate SA transition rates depend in part on changes in the composition of the populations at risk (see above). Consider first those at risk of entry (SA non-recipients). Averaging over the period as a whole, the mean age was 41 years, half the sample were women, and just over one half reported at least one health problem. About thirteen percent had no educational qualifications and a quarter had only low educational qualifications. Almost a half of non-recipients had at least one dependent child and just under a fifth had a child aged less than five years. Four-fifths were part of a couple, some 17 percent were single adults and 3 percent were lone parents. Just over 80 percent lived in owner-occupied accommodation, one in ten lived in the London area, and the average local area rate was just

\footnotetext{
${ }^{13}$ More precisely, the local area unemployment rate is the ratio of the number of unemployed to the number in the labor force for the respondent's TTWA at the time of the interview, derived from the Joint Unemployment \& Vacancies Operating System Cohort (a 5 percent sample of all computerized claims for unemployment-related benefits selected by reference to a claimant's National Insurance Number). TTWAs are defined with reference to commuting patterns, and correspond broadly to a city and surrounding area. See Cappellari and Jenkins (2008a) for more details of the construction of the series.

${ }^{14} \mathrm{We}$ also considered a quasi-differences-in-differences approach in which we also included interactions between the survey year indicators in $Z_{i t-1}$ and $W_{i t-1}$ and the presence of children: the reasoning is that the Labour government's reforms were directly primarily at families with children. As it happened, very few interaction variable coefficients were statistically significant, and the temporal pattern of the estimates did not
} 
over 5 percent. These whole-period averages disguise some marked trends over time. In particular, there was a rise in the proportion reporting a health problem (up from around 50 percent in 1991 to around 60 percent in 2005), and even larger changes in the distribution of educational qualifications. The fraction of non-recipients with no or low educational qualifications declined from around 53 percent in 1991 to 26 percent in 2005. The other main variation over time was in local area unemployment rates, which declined from almost 10 percent on average at the start of the 1990s to just over 2 percent in 2005. In contrast, the means of virtually all the demographic variables (age, number and age of children, family type) changed very little.

These changes suggest that one reason for the decline in SA entry rates may be the improvement in educational qualifications (improving employability) and the decline in local area unemployment rates reflecting improved availability of jobs. The rate of decline in the average local area unemployment rate leveled off around 1997, which is consistent with the leveling off in the decline in the entry rate around that year (Figure 2).

Consider now those at risk of SA exit. Averaging over the period as a whole, we find that compared to non-recipients, the proportion of female recipients is larger (60 percent rather than 50 percent), and the proportion with relatively low educational qualifications is higher (40 percent of recipients have no qualifications compared to 13 percent of nonrecipients). A quarter of recipients belong to families with three or more children (compared to 8 percent of recipients) and the proportion with a child aged less than five years is 25 percent rather than 18 percent. About one quarter of recipients are lone parents but only 3 percent of non-recipients. The proportion of SA recipients living in owned accommodation is only one third compared with 80 percent for non-recipients. In addition, recipients tend to live in areas with slightly higher unemployment rates than non-recipients. In sum, SA receipt is concentrated among individuals with characteristics commonly associated with labor market disadvantage.

As far as trends are concerned, there are both similarities and differences between SA recipients and non-recipients. For both groups, the prevalence of health problems rose between 1991 and 2005, but the increase is larger for recipients (from 53 percent to 76 percent, compared to from 50 percent to 59 percent). Local area unemployment rates fell for both groups; so too did the proportion with no educational qualifications but the decline in the latter was smaller for SA recipients than non-recipients. There are some distinctive 
demographic trends for recipients: the proportion with children, and with young children in particular, declined over time. There was also a decline in number of lone parents among recipients (from 35 percent in 1991 to 18 percent in 2005). In principle this might be explained by a shift in low income families with children (and lone parents in particular) from SA receipt to receipt of in-work benefits such as WFTC, but the proportions of couples with children and of lone parents was largely unchanged over the period. Another marked trend among recipients is the decline in the proportion living in owned accommodation, from 41 percent in 1991 to 22 percent in 2005. Put another way, the association between SA receipt and living in rented accommodation (much of which is subsidized social housing) has increased.

These patterns suggest that two trends in particular may help account for the decline in the aggregate SA exit rate over time: the rise in proportion of recipients with health problems, and the large rise in the proportion living in non-owned accommodation. Both trends are consistent with a 'creaming' hypothesis - the most skilled and work-ready individuals left SA for a job, whereas the group left on SA increasingly consisted of individuals who were less well equipped for work, and for whom the probability of SA exit is relatively low.

\section{MODEL ESTIMATES AND COUNTERFACTUAL SIMULATIONS}

\section{Model Estimates}

Estimates of the dynamic random effects probit model specified in (4) are set out in Table 3. In the top half of the table, the first column of numbers refers to estimates of $\gamma$ and the second column to estimates of $\lambda$. In the bottom half of the table are the estimates of the effects of the longitudinally-averaged variables on SA receipt propensities, the impact of being in SA receipt when initially observed, and the variance of the unobserved heterogeneity distribution.

Table 3 shows that SA entry probabilities are lower for women, individuals living with a partner, and without a child aged less than 5 years. There is a gradient in entry rates with educational qualifications - highest for those with no qualification and lower the higher the qualifications attained (and higher still for those with missing qualifications data). There 
is no statistically significant association between entry rates and age, the presence of health problems, number of children, home ownership, and residential location.

$<$ Table 3 near here $>$

The higher the local area unemployment rate, the higher the SA entry rate - which is consistent with the aggregate trend data shown in Figures 1 and 2.

The estimated coefficients on the survey year variables also correspond with the trends in aggregate data. (The year labels shown in Table 3 refer to year $t$ for transitions between year $t-1$ and year $t$.) Between the mid-1990s and the mid-2000s, the coefficients become increasingly negative implying a lower SA entry rate, other things equal. These appear to be large changes: the coefficient doubled in magnitude between 1995 and 2005, from -0.14 to -0.28 . But are there jumps in the coefficient estimates corresponding to years of major benefit reform - survey years 1997, 2000, and 2004 according to the labeling convention used in the table?

The estimates suggest that the introduction of JSA, accompanied by tightening of eligibility conditions, was associated with a decline in SA entry rates. For those at risk of entry in 1996 (year $t=1997$ ), the estimated coefficient is -0.17 , but it is -0.37 for those at risk of entry in 1997 (year $t=1998$ ). There is also some evidence consistent with a WFTC introduction effect as the coefficient for those at risk of entry in 1999 (year $t=2000$ ) is -0.24 , but -0.43 for those at risk of entry a year later. In contrast, there is no similar change in the coefficients for years round the change from WFTC to WTC.

We therefore find a smoking gun for some effects of benefit policy reform on SA entry rates. We are cautious about drawing stronger causal conclusions for the reasons described earlier.

What about the determinants of exit rates? Observe, first of all, that relatively few coefficients on the variables included in the vector of interactions between characteristics and lagged SA receipt status are statistically significant. The exceptions concern the number of children in the family and whether the respondent has a partner. Having more children is associated with a larger exit rate, whereas being a member of a couple is associated with lower exit rate. Otherwise, we find, for example and as expected, that having better educational qualifications is associated with a higher exit rate, and a larger unemployment rate is associated with a lower exit rate.

By contrast with the results for entry rates, there appears to be little evidence of benefit policy reform effects on exit rates. For the relevant survey years, observe that the sum of corresponding $\gamma$ and $\lambda$ coefficients is close to zero: the coefficients are of approximately 
the same magnitude and of the opposite sign. Hence the change in the sums between successive years is also negligible.

The estimates of the parameters associated with unobserved heterogeneity are at the bottom of Table 3. The table shows that individuals with a disposition to health problems or many children are more likely to receive SA. Family type and housing tenure also matter. Individuals who are more likely to be lone parents are more likely to receive SA, whereas individuals with a partner are less likely to. Home-owners are less likely to receive SA than renters. Experiencing persistently high local area unemployment rates does not appear to be associated with a high probability of SA receipt, other things being equal. (It is the year-toyear variations in unemployment that drive changes in SA receipt, by changing exit and entry propensities.) There is statistically significant unobserved heterogeneity in addition to the heterogeneity captured by the longitudinally-averaged variables: the estimate of $\sigma_{u}{ }^{2}$ is 0.42 . Finally, observe that initial conditions matter. Individuals who are receiving SA when initially observed are much more likely than non-recipients to be receiving SA in some subsequent year.

\section{Counterfactual Simulations to Assess the Drivers of Transition Rate Trends}

We now employ the model to assess the main drivers of the trends in aggregate annual SA entry and exit rates shown in Figure 2. Before embarking on the counterfactual simulations, we show first that the fitted model tracks the aggregate trends shown in Figure 2. Figure 3 shows these "within-sample” entry and exit rate predictions by year, and also reproduces the aggregate series shown earlier. Chart (a) compares entry rates; chart (b) compares exit rates.

In two respects, the predictions are poor. First, within-sample predictions consistently over-estimate both entry and exit rates. We do not have an explanation for this but suspect that it relates to the use of non-linear functions in (5) and (7). (We have checked that it is not related to skewness in the distribution of predicted probabilities.) Second, the predicted trend between the first two years of each series is in the wrong direction. (Again we do not have an explanation for this.) But these are the only two years for which this is the case.

We would emphasize that otherwise the within-sample predictions track trends over time remarkably well. Turning points in both aggregate transition rate series correspond to turning points in both within-sample series.

\footnotetext{
$<$ Figure 3 near here $>$
} 
Given this correspondence, we proceed to our counterfactual simulations. We consider the impact of four factors: falling unemployment rates, effects associated with the passage of time (which include any benefit policy reform effects), the secular improvement in educational qualifications, and changes in the distribution of housing tenure.

The first exercise concerns the impact of changing unemployment rates. To assess this, we consider what would have happened to SA entry and exit rates were unemployment remain at its 1993 peak, and everything else were to stay the same (including the values of the longitudinally-averaged variables and initial receipt status). Since the model is fitted to data on individual-specific local area unemployment rates, we first generate another set of within-sample estimates by replacing individual-specific local area unemployment rates within each year by the average rate among the relevant population at risk (there are different averages each year for SA recipients and non-recipients). This generates the transition rates series labeled "average unemployment rates" in Figure 4. This series is almost identical to the within-sample series shown in Figure 3. The counterfactual predictions are derived by replacing the average unemployment rates for each year with the average rates for 1993 in every year.

$<$ Figure 4 near here $>$

Figure 4 suggests that the fall in unemployment rates over the period had a large impact on SA entry rates. If unemployment had remained at its peak level, the entry rate would have been about 1 percentage point higher by 2005. This is a large impact given that the corresponding within-sample rate was 2 percent. Observe that most of impact of falling unemployment rates occurred before the turn of the $21^{\text {st }}$ century. (The decline in the rate leveled out around this time: see Figure 1.)

For SA exit rates, we see the impact expected: If unemployment rates had remained high, the exit rate would have been lower. However, the magnitude of the effect is small compared with the impact on the entry rate. The difference between the series is never more than 5 percentage points, which is small compared to an exit rate of between 40 percent and 50 percent.

Our second counterfactual exercise concerns factors associated with the passage of time, which includes potential benefit policy reform effects. To do this, we compare our original within-sample prediction series with predicted transition rates generated by fixing the coefficients on the survey year indicators at the value of the estimated coefficient for 1993. (All other factors remain unchanged.) The series are shown in Figure 5. For entry rates, the effects associated with the passage of time are large, and of approximately the same order of 
magnitude as the effect of falling unemployment rates. We would emphasize that this exercise does not show the size of the impact of any specific benefit policy reform, rather it indicates the overall impact associated with the passage of time. (At most, it provides an upper bound on the cumulative impact of policy changes.) The multivariate model estimates shown in Table 3 suggest that there were other factors besides policy reforms that were operational throughout the period as a whole. The simulations for exit rates (chart b) confirm the impressions derived from discussion of the regression table estimates: there was little clear evidence of policy reform or other time effects in this case. The counterfactual and within-sample series overlap substantially.

$<$ Figure 5 near here $>$

The third counterfactual exercise was motivated by the marked upgrading in educational qualifications among the working-age population. Our simulations consider what would have happened to transition rates were the distribution of educational qualifications across the four categories (none, low, high and missing) to have remained as it was in 1991. In order to provide comparable within-sample predictions, we replaced actual educational qualifications in each year with the relevant sample proportion for that year (analogous to what we did for the unemployment simulation exercise). The results are summarized in Figure 6. For entry rates, we see an effect in the expected direction: without the secular upgrading, the SA entry rate would have been higher. However the magnitude of the effect is small relative to the effects of falling unemployment rates or "time". For exit rates, there is what appears at first sight to be counter-intuitive result: exit rates are predicted to be higher when the distribution of educational qualifications is fixed at thee 1991 distribution. We resolve this puzzle by noting the particular nature of the upgrading of education qualifications among SA recipients. What is relevant for the simulations is not a the average of a single “education” variable, but a distribution across four educational qualification categories. As pointed out in the previous section, the fraction of SA recipients with no qualifications did not decline over time as fast as for non-recipients, and was higher in the first place. (By 2005, one third of SA recipients were in the no qualifications category but only 6 percent of nonrecipients.) So, we believe the simulation results shown in the figure reflect the deterioration over time in the distribution of qualifications of SA recipients relative to non-recipients.

$<$ Figure 6 near here $>$

In a fourth counterfactual exercise, we consider the impact of changing home ownership patterns over time, noting in particular the drop over the 1991-2005 period in the proportion of SA recipients who are owner-occupiers from around 40 percent to around 20 
percent. (Among non-recipients, the corresponding fraction remained relatively constant at just over 80 percent.) We considered what entry and exit rates would have been were the proportions of owner-occupiers among SA recipients and non-recipients had remained at their 1991 levels. As it happens, there was no impact at all on either entry rates or exit rates. The within-sample and counterfactual series coincided in both cases (charts not shown for brevity).

\section{Heterogeneity in Transition Rates}

Finally, we embark on a different type of simulation exercise. So far, the simulations have been concerned with generating predictions of aggregate transition rates and their trends over time. This involved averaging of individual-level predictions and hence information about the degree of heterogeneity in transition rates across individuals with different characteristics was hidden. We now illustrate this heterogeneity by predicting SA entry and exit rates for an individual with a specific "base” set of characteristics, and compare these predictions with derived by changing each of a number of characteristics one at a time. The predictions refer to a particular year. The results are shown in Table 4. The "base" set of characteristics refer to a woman aged 40 years, who is an owner-occupier living outside London, who is married with one child under 5 , who has no health problems and no educational qualifications, and the local are unemployment rate is 3 percent, and the year is $=2005$. She did not receive SA in the year she was initially observed.

The predicted entry probability for this person is 1.2 percent, and the predicted exit probability is 85.4 percent. If, instead, the person received SA when initially observed, then the entry probability is a massive five times larger, and the exit probability one quarter lower (row 2). Men and women have much the same entry and exit probabilities (row 3). More important than gender is family type. If the reference woman is a lone mother rather than married., then her entry probability more than trebles to 3.9 percent, and her exit probability falls by about a quarter to 68.6 percent (row 7). If in addition the woman is not an owneroccupier, the entry probability is a massive 14.6 percent and the exit probability is half that of the base case, 41.6 percent (row 8). Differences in housing tenure alone are associated with large differences in transition probabilities (row 7). Not having children almost halves the entry probability, and slightly increases the exit probability (row 9). Finally, observe that if the year is changed from 2005 to 1993 and the local area unemployment rate from 3 percent to 9 percent, then the entry probability more than doubles (from 1.2 percent to 3.3 percent) 
and the exit probability hardly changes. This underlines our earlier remarks regarding the importance of changes in entry rates

$<$ Table 4 near here $>$

\section{SUMMARY AND CONCLUSIONS}

We have analyzed the dynamics of SA receipt among working-age adults in Britain between 1991 and 2005, making the case that the near-halving in the aggregate annual receipt rate over this period was driven by a decline in the annual entry rate rather than changes in the annual exit rate (which actually declined). To examine the determinants of trends in aggregate SA transition rates, we have developed an innovative dynamic random effects probit model of SA receipt entry and exit probabilities, fitted it to BHPS data, and used the estimates to provide counterfactual simulations of trends in SA transition rates.

Our analysis indicates that two sets of factors were the major determinants of transition rate trends and the counterfactual simulation exercises suggest that they had approximately equal-sized effects. First, there is the increasing health of the labor market, which we documented in terms of the fall in unemployment rates that occurred between 1993 and the mid-2000s. If the current recession leads to a rise in unemployment rates that reverses the earlier decline, our results suggest that SA receipt rates will rise substantially.

Second, there were a number of other changes between 1991 and 2005 in the socioeconomic environment including, in particular, various reforms to the income maintenance system in the 1990s. Our results suggest that two reforms had an effect on SA entry rates: the introduction of JSA in 1996 (by making it harder to claim), and the introduction of WFTC in 1999 (making work pay and hence SA less attractive). Investigating the extent to which these effects on SA receipt are genuinely causal is a task for future research; so too is analysis of the nature of other changes in the socioeconomic environment that were associated with the fall in the SA entry rate. 


\section{REFERENCES}

Andrén, T. (2007). The persistence of welfare participation. Working Papers in Economics No 266. Göteborg: University,School of Business, Economics and Law, Göteborg University. http://hdl.handle.net/2077/7366

Akay, A. (2009). 'The Wooldridge method for the initial values problem is simple: what about performance?’ IZA Discussion Paper 3943. Bonn: Institute for the Study of Labour (IZA). ftp://repec.iza.org/RePEc/Discussionpaper/dp3943.pdf

Arulampalam, W., \& Stewart, M.B. (2009). Simplified implementation of the Heckman estimator of the dynamic probit model and a comparison with alternative estimators. Oxford Bulletin of Economics and Statistics, 71(5), 659-681.

Bane, M.J., \&. Ellwood, D.T. (1983). The dynamics of dependence: The routes to selfsufficiency. Report to US Department of Health and Human Services, Urban Systems Research and Engineering, Cambridge MA.

Bane, M.J., \&. Ellwood, D.T. (1994). Welfare realities: From rhetoric to reform. Cambridge MA: Harvard University Press.

Blundell, R. (2001). Welfare reform for low income workers. Oxford Economic Papers, 53(2), 189-214.

Blundell, R. \& Hoynes, H. (2004). Has in-work benefit reform helped the labour market? In R. Blundell, D. Card \& R.B. Freeman (Eds.), Seeking a Premier Economy: The Economic Effects of British Economic Reforms, 1980-2000. Chicago, IL: University of Chicago Press.

Brewer, M. \& Shephard, A. (2004). Has Labour made work pay? York: York Publishing Services for the Joseph Rowntree Foundation. http://www.jrf.org.uk/bookshop/eBooks/1859352626.pdf

Brewer, M., Duncan, A., Shephard, A., \& Suarez, M.J. (2006). Did working families’ tax credit work? The impact of in-work support on labour supply in Britain. Labour Economics, 13(6), 699-720.

Brewer, M., Francesconi, M., Gregg, P., \& Grogger, J. (2009). In-work benefit reform in a cross-national perspective - Introduction. Economic Journal, 119 (535), F1-F14.

Cappellari, L., \& Jenkins, S.P. (2004). Modelling low income transitions. Journal of Applied Econometrics, 19(5), 593-610.

Cappellari, L., \& Jenkins, S.P. (2008a). The dynamics of social assistance receipt: measurement and modelling issues, with an application to Britain. Social, 
Employment and Migration Working Paper 67. Paris: OECD.

http://www.oecd.org/dataoecd/30/42/41414013.pdf.

Cappellari, L., \& Jenkins, S.P. (2008b). Estimating low pay transition probabilities accounting for endogenous selection mechanisms. Journal of the Royal Statistical Society, Series C (Applied Statistics), 57(2), 165-186.

Chamberlain, G. (1984). Panel data. In Z. Griliches \& M. Intrilligator (Eds.), Handbook of Econometrics. Amsterdam: North-Holland.

Chay, K.Y. \& Hyslop, D. (2000). Identification and estimation of dynamic binary response panel data models: empirical evidence using alternative approaches. Unpublished Paper, University of California Berkeley. http://www.econ.berkeley.edu/ kenchay/ftp/binresp/working_paper/hyslop.pdf

Francesconi, M. \& van der Klaauw, W. (2007). The socioeconomic consequences of in-work benefit reform for British lone mothers. Journal of Human Resources, 42(1), 1-31.

Gregg, P., Harkness, S., \& Smith, S. (2009). Welfare reform and lone parents in the UK. Economic Journal, 119(535), F38-F65.

Grogger, J. (2004). Welfare transitions in the 1990s: the economy, welfare policy, and the EITC. Journal of Policy Analysis and Management, 32(4), 671-695.

Haider, S., \& Klerman, J.A. (2005). Dynamic properties of the welfare caseload. Labour Economics, 12(5), 629-648.

Hansen, J., \& Lofstrom, M. (2006). Immigrant-native differences in welfare participation: the role of entry and exit rates. IZA Discussion Paper No. 2261. Bonn: Institute for the Study of Labour (IZA). ftp://repec.iza.org/RePEc/Discussionpaper/dp2261.pdf

Hansen, J., Lofstrom, M., \& Zhang, X. (2006). State dependence in Canadian welfare participation. IZA Discussion Paper No. 2266. Bonn: Institute for the Study of Labour (IZA). ftp://repec.iza.org/RePEc/Discussionpaper/dp2266.pdf

Heckman, J.J. (1981). The incidental parameters problem and the problem of initial conditions in estimating a discrete time-discrete data stochastic process. In C.F. Manski \& D. McFadden (Eds.), Structural analysis of discrete data with econometric applications. Cambridge, MA: MIT Press.

Immervoll, H. (2009). Minimum-income benefits in OECD countries: policies and challenges, Unpublished paper. Paris: OECD.

Jenkins, S.P. (2000). Modelling household income dynamics. Journal of Population Economics, 13(4), 529-567. 
Manning, A. (2009). You can't always get what you want: The impact of the UK Jobseeker's Allowance. Labour Economics, 16(3), 239-250.

Midgley, J. (2008). Welfare reform in the United States: Implications for British social policy. CASEpaper 131. London: Centre for the Analysis of Social Exclusion, London School of Economics. http://sticerd.lse.ac.uk/dps/case/cp/CASEpaper131.pdf

Mundlak, Y. (1978). On the pooling of time series and cross section data. Econometrica, 46(1), 69-85.

Orme, C.D. (2001). Two-step inference in dynamic non-linear panel data models.

Unpublished paper, University of Manchester.

http://personalpages.manchester.ac.uk/staff/chris.orme/documents/Research\%20Paper s/initcondlast.pdf

Petrongolo, B. (2007). What are the long-term effects of UI? Evidence from the UK JSA reform. Discussion Paper No 841. London: Centre for Economic Performance, London School of Economics. http://cep.lse.ac.uk/pubs/download/dp0841.pdf. Journal of Public Economics, forthcoming.

Ribar, D.C. (2005). Transitions from welfare and the employment prospects of low-skill workers. Southern Economic Journal, 71(3), 514-533.

Stewart, M.B. (2007). The interrelated dynamics of unemployment and low pay. Journal of Applied Econometrics, 22(3), 511-531.

Walker, R. (2005). Social security and welfare: concepts and comparisons. Milton Keynes: Open University Press/McGraw-Hill.

Wooldridge, J.M. (2005). Simple solutions to the initial conditions problem in dynamic, nonlinear panel data models with unobserved heterogeneity. Journal of Applied Econometrics, 20(1), 39-54. 
Table 1. The principal social assistance benefits in the UK today for working age adults

\begin{tabular}{ll}
\hline Benefit & Eligibility conditions (main) \\
\hline Income Support & $\begin{array}{l}\text { Income less than a specified minimum level, and unavailable } \\
\text { for full-time work (e.g. lone parent, registered sick or disabled, } \\
\text { caring for someone who’s sick or elderly). }\end{array}$ \\
$\begin{array}{l}\text { Job Seekers Allowance } \\
\text { (income based) }\end{array}$ & $\begin{array}{l}\text { Income less than a specified minimum level, and unemployed } \\
\text { but able to work and available to work (which has to be } \\
\text { regularly declared). }\end{array}$ \\
Housing Benefit & $\begin{array}{l}\text { Income less than a specified minimum level, and needing } \\
\text { financial help to pay all or part of one’s housing costs. }\end{array}$ \\
Council Tax Benefit & $\begin{array}{l}\text { Income less than a specified minimum level, and needing } \\
\text { financial help to pay all or part of one’s Council Tax bill. }\end{array}$ \\
\hline
\end{tabular}

Notes: Income Support was introduced in 1988 (its predecessor was called Supplementary Benefit). Housing Benefit was introduced in 1983 and Council Tax Benefit in 1993. Job Seekers Allowance was introduced in 1996. See also Table 2 below regarding changes between 1991 and 2005.

Table 2. Principal changes to the UK system of cash benefits and tax credits, 1991-2005

\begin{tabular}{|c|c|}
\hline $\begin{array}{l}\text { Year of } \\
\text { introduction }\end{array}$ & Change \\
\hline 1996 & $\begin{array}{l}\text { Job Seekers Allowance (JSA) introduced in October } 1996 \text { with “income } \\
\text { based” and “contribution based” components. JSA replaced Income Support } \\
\text { (IS) and Unemployment Benefit (UB) for unemployed jobseekers. } \\
\text { Accompanied by more stringent job search requirements for those assessed as } \\
\text { available for work. IS became available only to those not available for work. }\end{array}$ \\
\hline 1999 & $\begin{array}{l}\text { Working Families Tax Credit (WFTC) introduced in October 1999, and fully } \\
\text { phased in by April 2000. This in-work benefit program for low income } \\
\text { families was more generous and widened eligibility relative to its predecessor, } \\
\text { the Family Credit program (FC). FC, introduced in 1988, replaced Family } \\
\text { Income Supplement (FIS) which began in 1971. Administered by the income } \\
\text { tax authorities (HM Revenue and Customs) rather then the benefits authorities } \\
\text { (Department for Work and Pensions, and Benefits Agency). }\end{array}$ \\
\hline 1999 & $\begin{array}{l}\text { Increased support for families with children, including increases in Child } \\
\text { Benefit (flat-rate payment per child, paid regardless of parental work status or } \\
\text { income), and increases in the child allowances in other benefits. }\end{array}$ \\
\hline 1999 & National Minimum Wage introduced. \\
\hline 2003 & $\begin{array}{l}\text { WFTC replaced by the Working Tax Credit (WTC) and Child Tax Credit } \\
\text { (CTC) programs from April 2003. WTC extended eligibility to single people } \\
\text { and to families without children. CTC unified child allowances across benefits. }\end{array}$ \\
\hline
\end{tabular}

Note. See Brewer and Shephard (2004) for a concise overview of the Labour government's welfare to work policies and associated changes in the benefit system. 
Table 3. The probability of SA receipt (dynamic random effect probit model estimates)

\begin{tabular}{|c|c|c|c|c|}
\hline Explanatory variables (measured at $t-1$ ) & $\gamma$ & & $\lambda$ & \\
\hline Female & $\begin{array}{c}-0.0895 \\
(0.034)\end{array}$ & $* * *$ & $\begin{array}{l}0.0896 \\
(0.060)\end{array}$ & \\
\hline Aged 50 years or more & $\begin{array}{c}0.0529 \\
(0.044)\end{array}$ & & $\begin{array}{c}0.0463 \\
(0.081)\end{array}$ & \\
\hline Has health problem(s) & $\begin{array}{l}0.0278 \\
(0.038)\end{array}$ & & $\begin{array}{c}-0.0143 \\
(0.057)\end{array}$ & \\
\hline \multicolumn{5}{|l|}{ Educational qualifications } \\
\hline Low: O-level(s), CSE, etc & $\begin{array}{c}-0.2073 \\
(0.046)\end{array}$ & $* * *$ & $\begin{array}{c}-0.0534 \\
(0.071)\end{array}$ & \\
\hline High: A-level(s) or higher & $\begin{array}{c}-0.3623 \\
(0.045)\end{array}$ & $* * *$ & $\begin{array}{c}-0.0680 \\
(0.073)\end{array}$ & \\
\hline Missing data & $\begin{array}{c}-0.4215 \\
(0.063)\end{array}$ & $* * *$ & $\begin{array}{l}0.0318 \\
(0.150)\end{array}$ & \\
\hline Number of children in family & $\begin{array}{c}-0.0264 \\
(0.024)\end{array}$ & & $\begin{array}{c}0.0751 \\
(0.027)\end{array}$ & $* * *$ \\
\hline Age of youngest child $<5$ years & $\begin{array}{c}0.1540 \\
(0.049)\end{array}$ & $* * *$ & $\begin{array}{c}-0.1084 \\
(0.073)\end{array}$ & \\
\hline Family type: lone parent & $\begin{array}{c}-0.0030 \\
(0.095)\end{array}$ & & $\begin{array}{l}0.0724 \\
(0.110)\end{array}$ & \\
\hline Family type: couple & $\begin{array}{c}-0.1214 \\
(0.069)\end{array}$ & $*$ & $\begin{array}{c}-0.2342 \\
(0.079)\end{array}$ & $* * *$ \\
\hline House tenure: owned & $\begin{array}{c}-0.0491 \\
(0.056)\end{array}$ & & $\begin{array}{l}0.0145 \\
(0.059)\end{array}$ & \\
\hline Lives in London (inner or outer) & $\begin{array}{l}0.2402 \\
(0.163)\end{array}$ & & $\begin{array}{l}0.0472 \\
(0.091)\end{array}$ & \\
\hline Unemployment rate in local area (\%) & $\begin{array}{l}0.0323 \\
(0.010)\end{array}$ & $* * *$ & $\begin{array}{r}-0.0107 \\
(0.015)\end{array}$ & \\
\hline \multicolumn{5}{|l|}{ Survey year (year $t$ ) } \\
\hline 1993 & $\begin{array}{c}-0.0321 \\
(0.058)\end{array}$ & & $\begin{array}{c}0.0049 \\
(0.118)\end{array}$ & \\
\hline 1994 & $\begin{array}{c}-0.0964 \\
(0.060)\end{array}$ & & $\begin{array}{c}-0.0659 \\
(0.121)\end{array}$ & \\
\hline 1995 & $\begin{array}{c}-0.1372 \\
(0.060)\end{array}$ & $* *$ & $\begin{array}{l}0.0462 \\
(0.122)\end{array}$ & \\
\hline 1996 & $\begin{array}{c}-0.1559 \\
(0.061)\end{array}$ & $* *$ & $\begin{array}{l}0.0013 \\
(0.124)\end{array}$ & \\
\hline 1997 & $\begin{array}{c}-0.1734 \\
(0.067)\end{array}$ & $* * *$ & $\begin{array}{l}0.1401 \\
(0.135)\end{array}$ & \\
\hline 1998 & $\begin{array}{c}-0.2914 \\
(0.077)\end{array}$ & $* * *$ & $\begin{array}{l}0.2572 \\
(0.147)\end{array}$ & $*$ \\
\hline 1999 & -0.3655 & $* * *$ & 0.3811 & $* *$ \\
\hline
\end{tabular}




\begin{tabular}{|c|c|c|c|c|}
\hline & $(0.082)$ & & $(0.154)$ & \\
\hline \multirow[t]{2}{*}{2000} & -0.2357 & $* * *$ & 0.2633 & $*$ \\
\hline & $(0.080)$ & & $(0.157)$ & \\
\hline \multirow[t]{2}{*}{2001} & -0.4262 & $* * *$ & 0.4703 & $* * *$ \\
\hline & $(0.089)$ & & $(0.165)$ & \\
\hline \multirow[t]{2}{*}{2002} & -0.3834 & $* * *$ & 0.3103 & * \\
\hline & $(0.089)$ & & $(0.167)$ & \\
\hline \multirow[t]{2}{*}{2003} & -0.3152 & $* * *$ & 0.5179 & $* * *$ \\
\hline & $(0.088)$ & & $(0.176)$ & \\
\hline \multirow[t]{2}{*}{2004} & -0.3991 & $* * *$ & 0.2557 & \\
\hline & $(0.092)$ & & $(0.173)$ & \\
\hline \multirow[t]{2}{*}{2005} & -0.2847 & $* * *$ & 0.4109 & $* *$ \\
\hline & $(0.090)$ & & $(0.181)$ & \\
\hline \multirow[t]{2}{*}{ Intercept } & -1.5693 & $* * *$ & 1.2370 & $* * *$ \\
\hline & $(0.102)$ & & $(0.180)$ & \\
\hline \multicolumn{5}{|l|}{ Longitudinally-averaged variables } \\
\hline \multirow[t]{2}{*}{ Has health problems } & 0.2495 & $* * *$ & & \\
\hline & $(0.055)$ & & & \\
\hline \multirow[t]{2}{*}{ Family type: couple } & -0.1473 & $*$ & & \\
\hline & $(0.081)$ & & & \\
\hline \multirow[t]{2}{*}{ Family type: lone parent } & 0.6074 & $* * *$ & & \\
\hline & $(0.121)$ & & & \\
\hline \multirow[t]{2}{*}{ Number of children in family } & 0.0964 & $* * *$ & & \\
\hline & $(0.031)$ & & & \\
\hline \multirow[t]{2}{*}{ Age of youngest child $<5$ years } & -0.0054 & & & \\
\hline & $(0.085)$ & & & \\
\hline \multirow[t]{2}{*}{ House tenure: owned } & -0.7970 & $* * *$ & & \\
\hline & $(0.068)$ & & & \\
\hline \multirow[t]{2}{*}{ Lives in London (inner or outer) } & -0.2498 & & & \\
\hline & $(0.171)$ & & & \\
\hline \multirow[t]{2}{*}{ Unemployment rate in local area (\%) } & 0.0118 & & & \\
\hline & $(0.009)$ & & & \\
\hline \multirow[t]{2}{*}{ Received SA at $t=1$} & 0.7658 & $* * *$ & & \\
\hline & $(0.051)$ & & & \\
\hline \multirow[t]{2}{*}{$\sigma_{u}^{2}$} & 0.4201 & $* * *$ & & \\
\hline & $(0.036)$ & & & \\
\hline
\end{tabular}

Notes. Table shows authors' estimates of equation (4) model fitted to data from waves 1-15 of the BHPS using the Wooldridge (2005) estimator. Standard errors in parentheses. ${ }^{*} p<0.10,{ }^{* *} p<0.05$, ${ }^{* * *} p<0.01$. Loglikelihood $=-8792.293$. Number of person-year observations $=66,952$. Number of persons $=9,036$. Reference categories: male, aged 25-50, has no health problems, has no educational qualifications, family type is single, lives in non-owned accommodation outside the London area, and the survey year is 1992. The outcome is measured in year $t$, and explanatory variables in year $t-1$, with the exception of the survey year indicators for which the indicator label refers to year $t$. 
Table 4. Heterogeneity in SA annual entry and exit rates: predicted transition probabilities for different types of person

\begin{tabular}{lll}
\hline Characteristics & Entry probability & Exit probability
\end{tabular}

(\%)

1.2

5.2

1.4

2.1

0.5

5.9

3.9

14.6

0.7

3.3
(\%)

85.4

65.9

85.4

79.7

91.3

63.9

68.6

41.6

88.7

84.5

10. Year is 1993, local area unemployment rate $=9 \%$

Notes. Predictions derived by authors using equations (5) and (7). * Base characteristics: woman, 40 years old, living outside London, one child under 5 , married , no health problems, no educational qualifications, local area unemployment rate $=3 \%$, owner-occupier, year $=2005$, not receiving SA in year initially observed. 
Figure 1. Proportion of working-age adults receiving social assistance benefits and tax credits, and the unemployment rate, by year

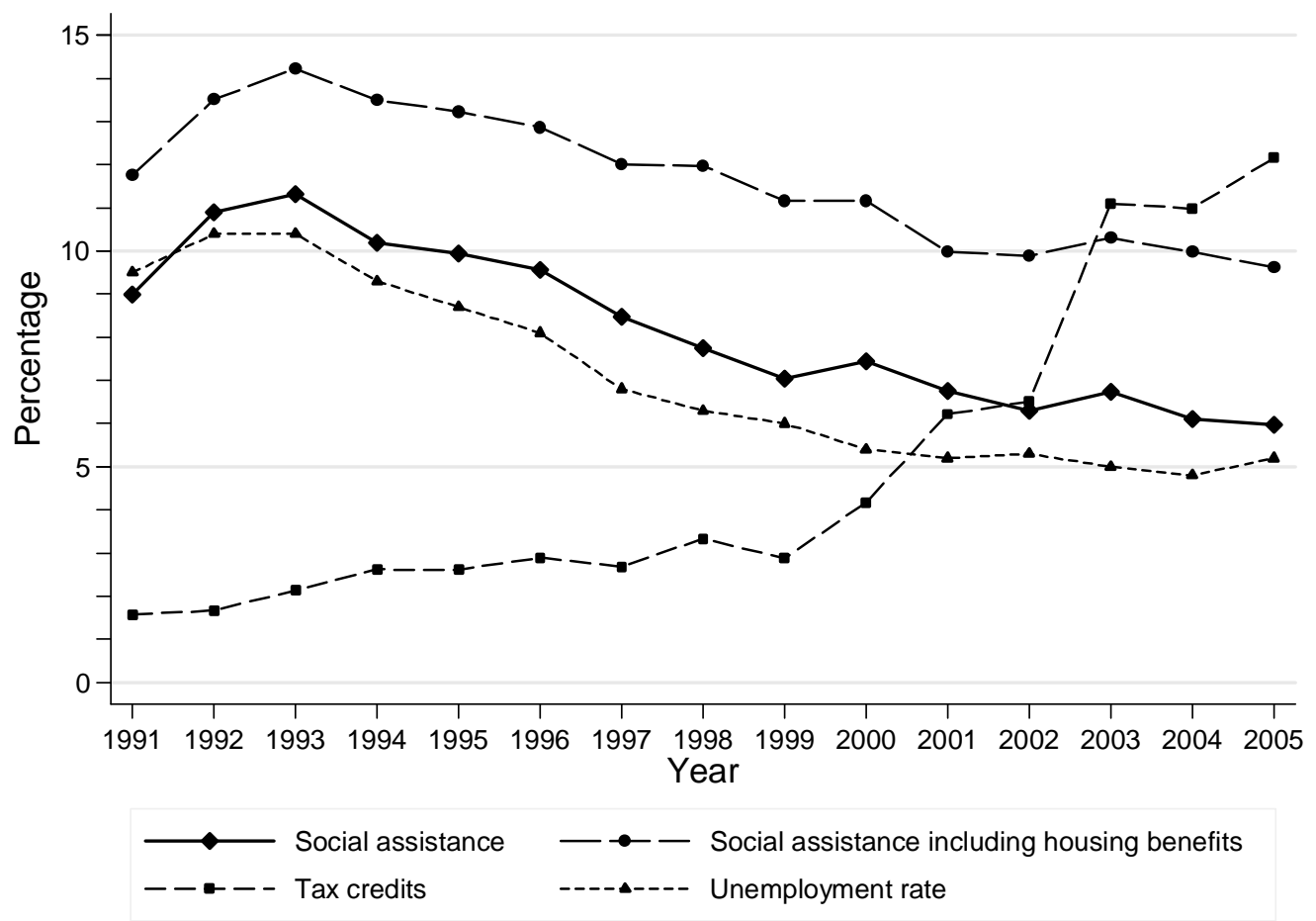

Notes: Authors' calculations using data from waves 1-15 of the British Household Panel Survey (BHPS), except for the unemployment rate which is series YBTI from the UK Office for National Statistics,

http://www.ons.gov.uk. The unemployment rate is the ILO unemployment rate for all adults (men aged 16-64, women aged 16-59), derived from the Labour Force Survey, and is a three-month average centered on the October of the year in question. The definitions of social assistance, housing benefits, and tax credits are explained later. 
Figure 2. Annual rates of entry to and exit from social assistance benefit receipt: workingage adults, by year

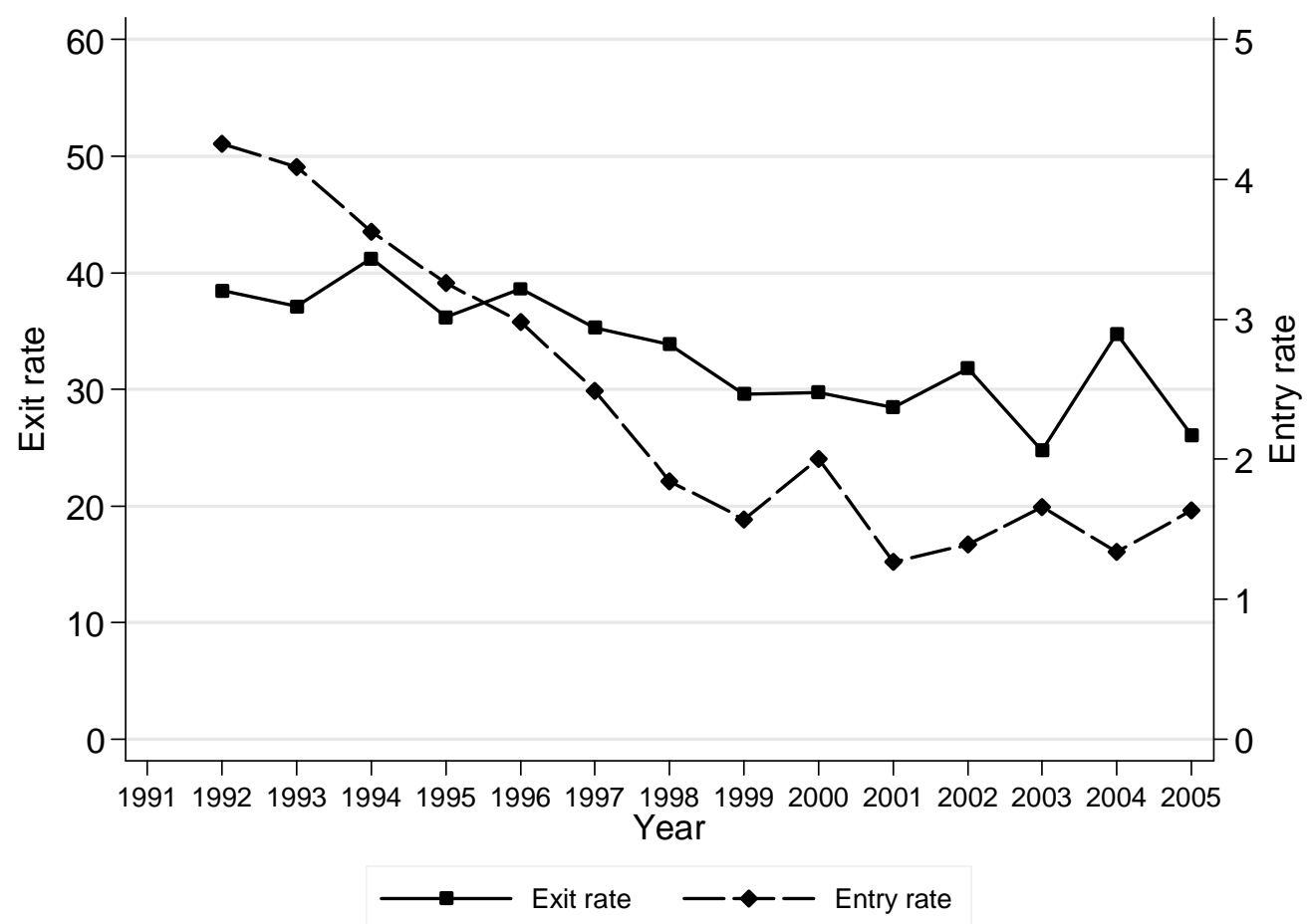

Notes: Authors' calculations using BHPS data. The definition of social assistance benefit receipt is explained later. 
Figure 3. Within-sample predictions of SA transition rates compared to aggregate transition rates

(a) Entry rates

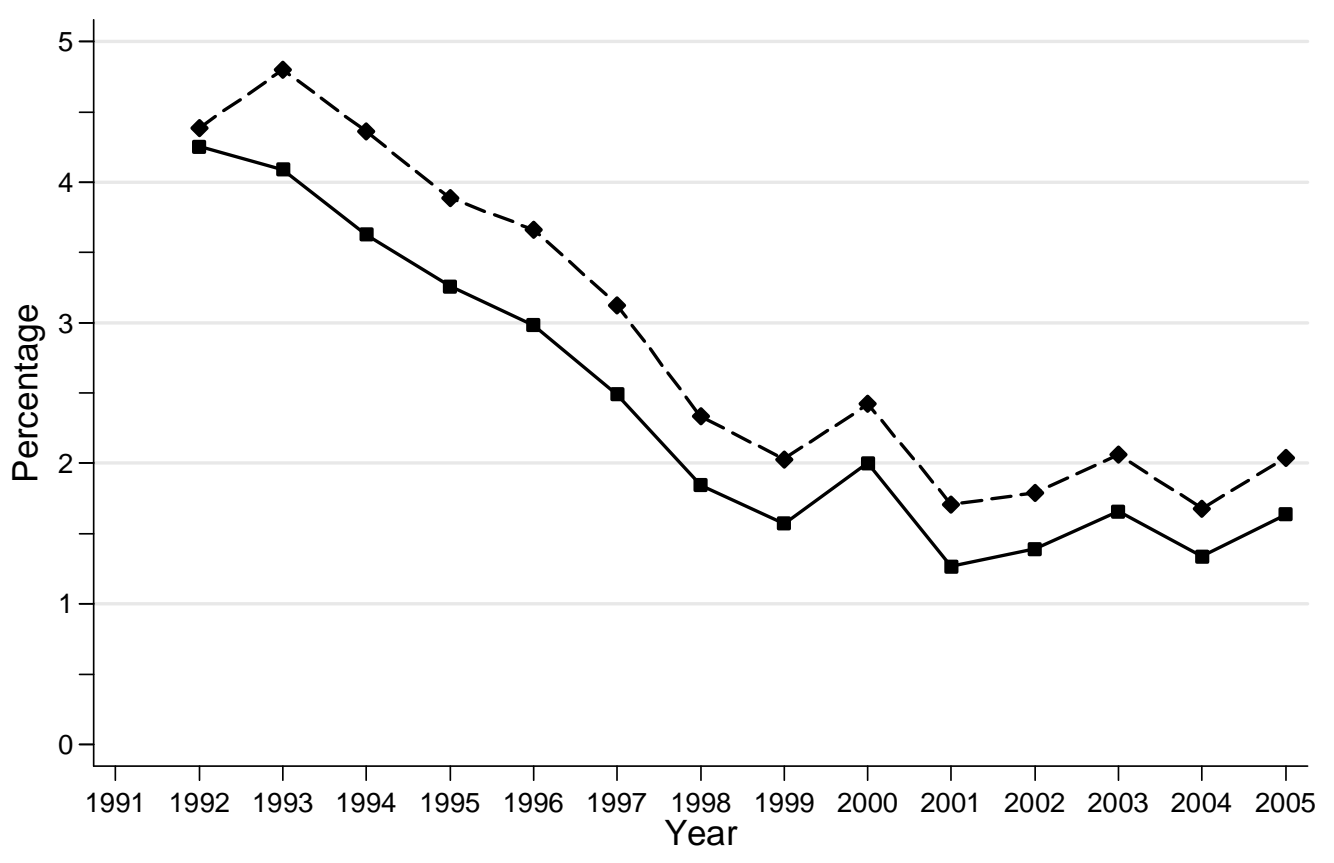

$\longrightarrow$ Entry rate $\quad--\bullet--$ Entry rate, within-sample prediction

(b) Exit rates

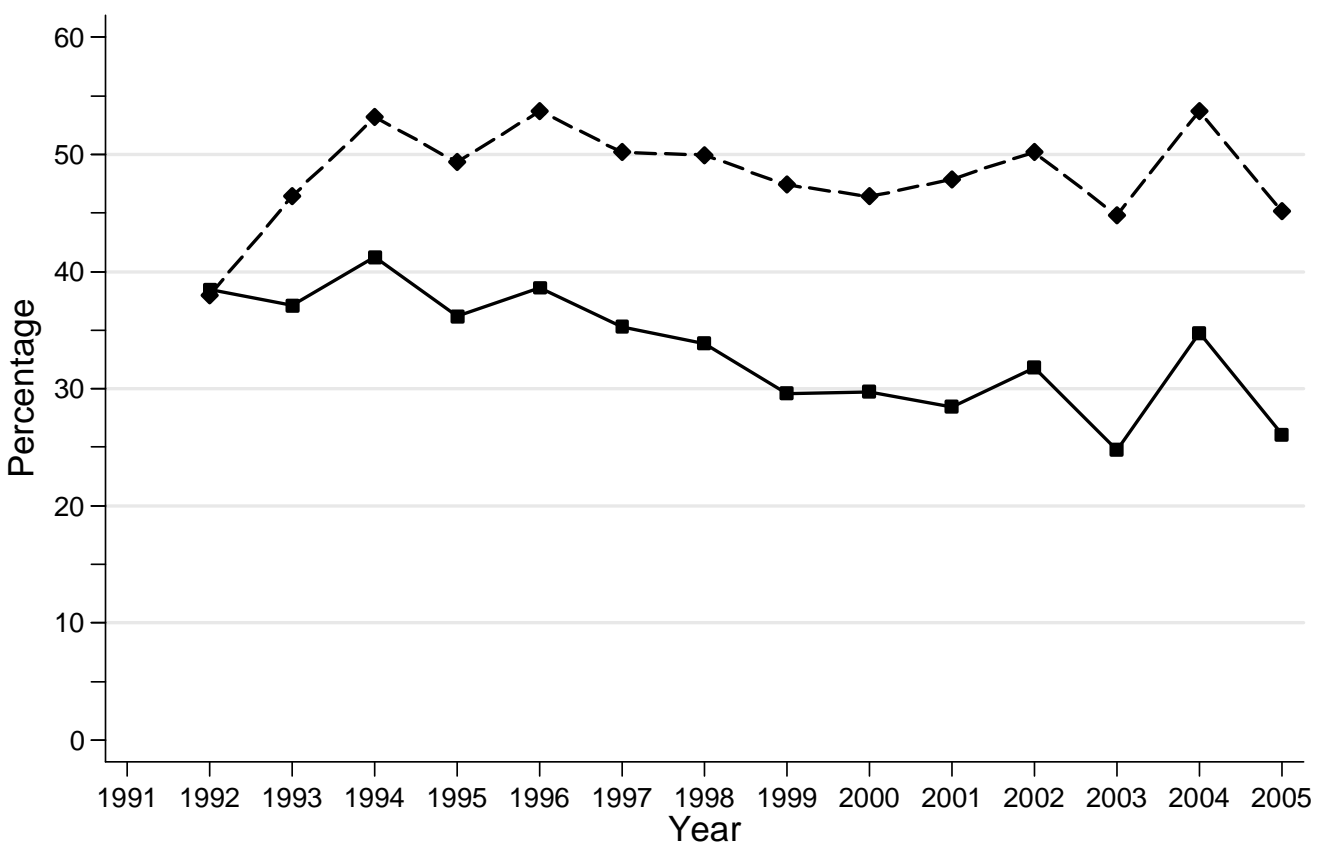

$\longrightarrow$ Exit rate $\quad-\bullet--$ Exit rate, within-sample prediction

Note. Authors' calculations from BHPS data using the parameter estimates shown in Table 3. The construction of the within-sample series is explained in the text. The aggregate entry and exit rates series are the same as those shown in Figure 2. 
Figure 4. Counterfactual simulations of SA transition rates: what if local area unemployment rates were fixed at the 1993 average value?

(a) Entry rates

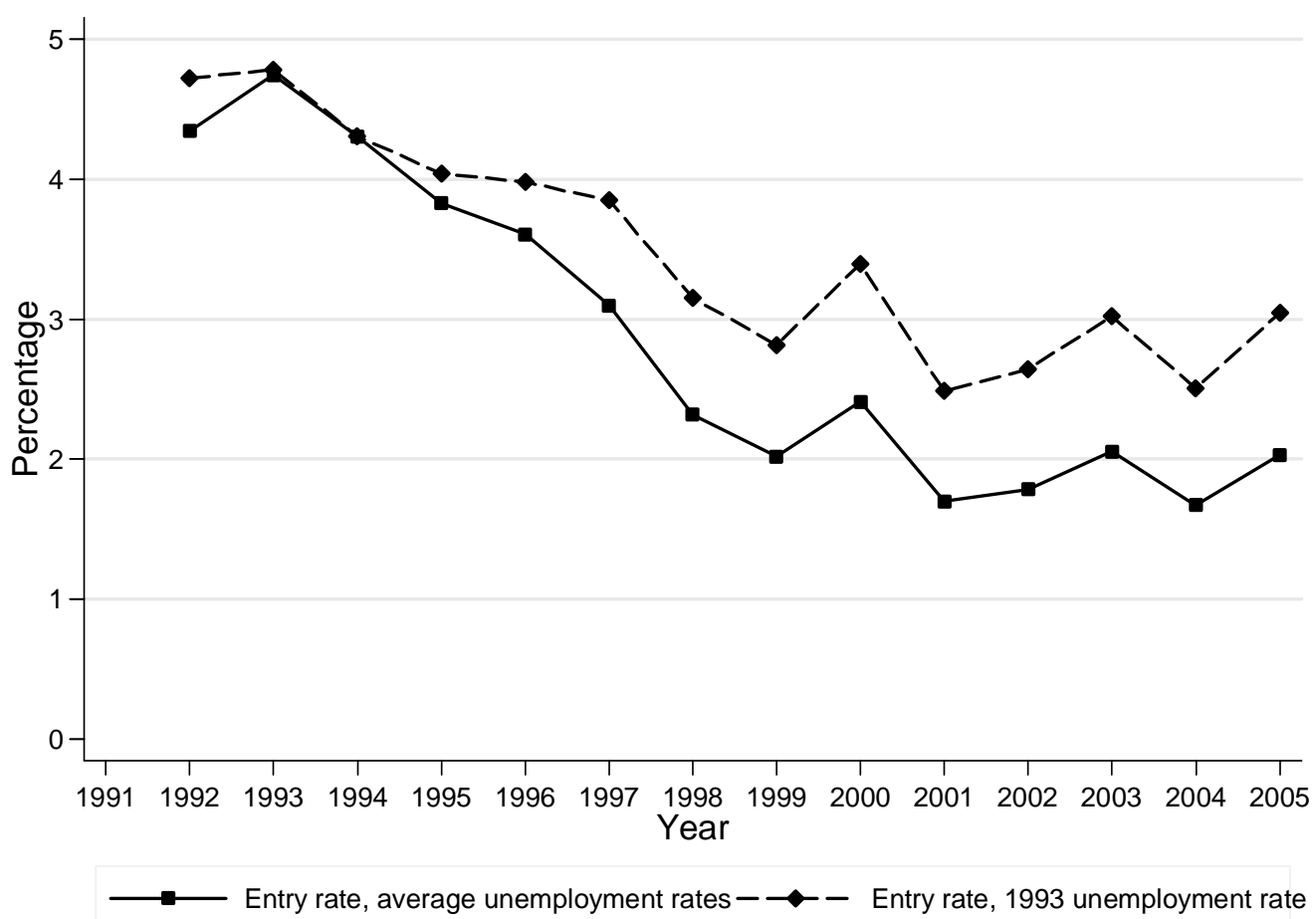

(b) Exit rates

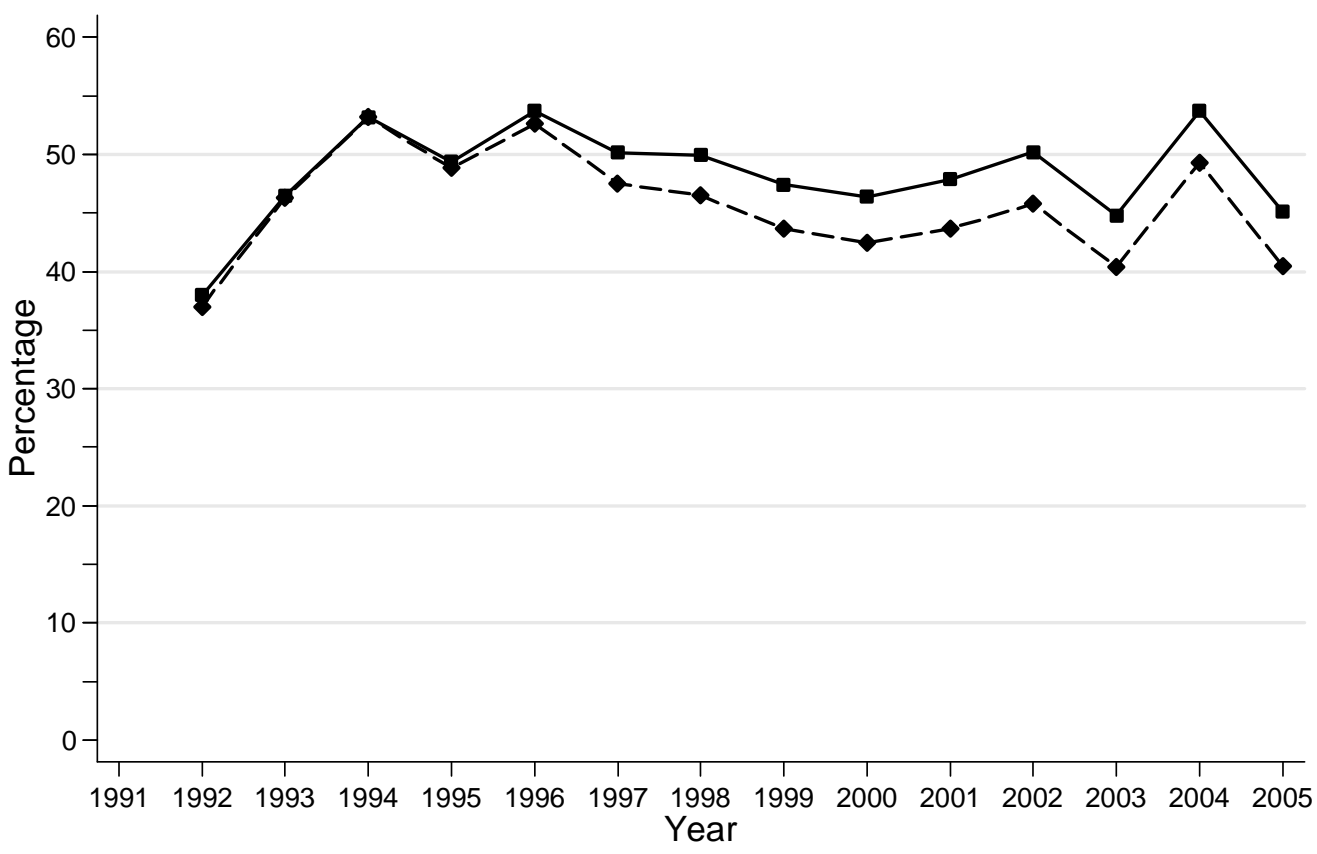

$\longrightarrow$ Exit rate, average unemployment rates $\longrightarrow \longrightarrow$ Exit rate, 1993 unemployment rate

Note. Authors' calculations from BHPS data using parameter estimates shown in Table 3. The construction of the reference and counterfactual series is explained in the text. 
Figure 5. Counterfactual simulations of SA transition rates: what if the survey year coefficients were all fixed at the value of the coefficients for 1993?

(a) Entry rates

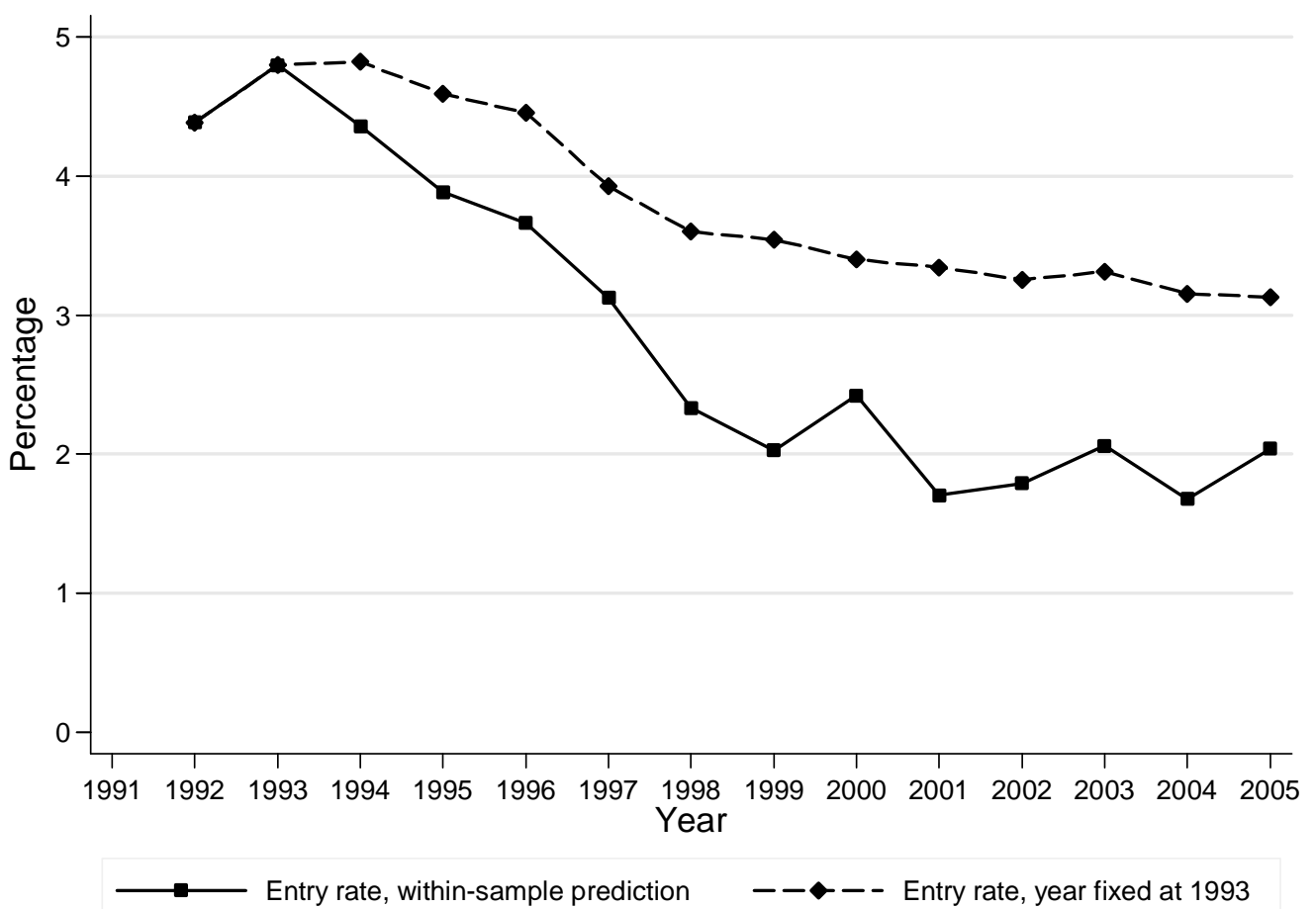

(b) Exit rates

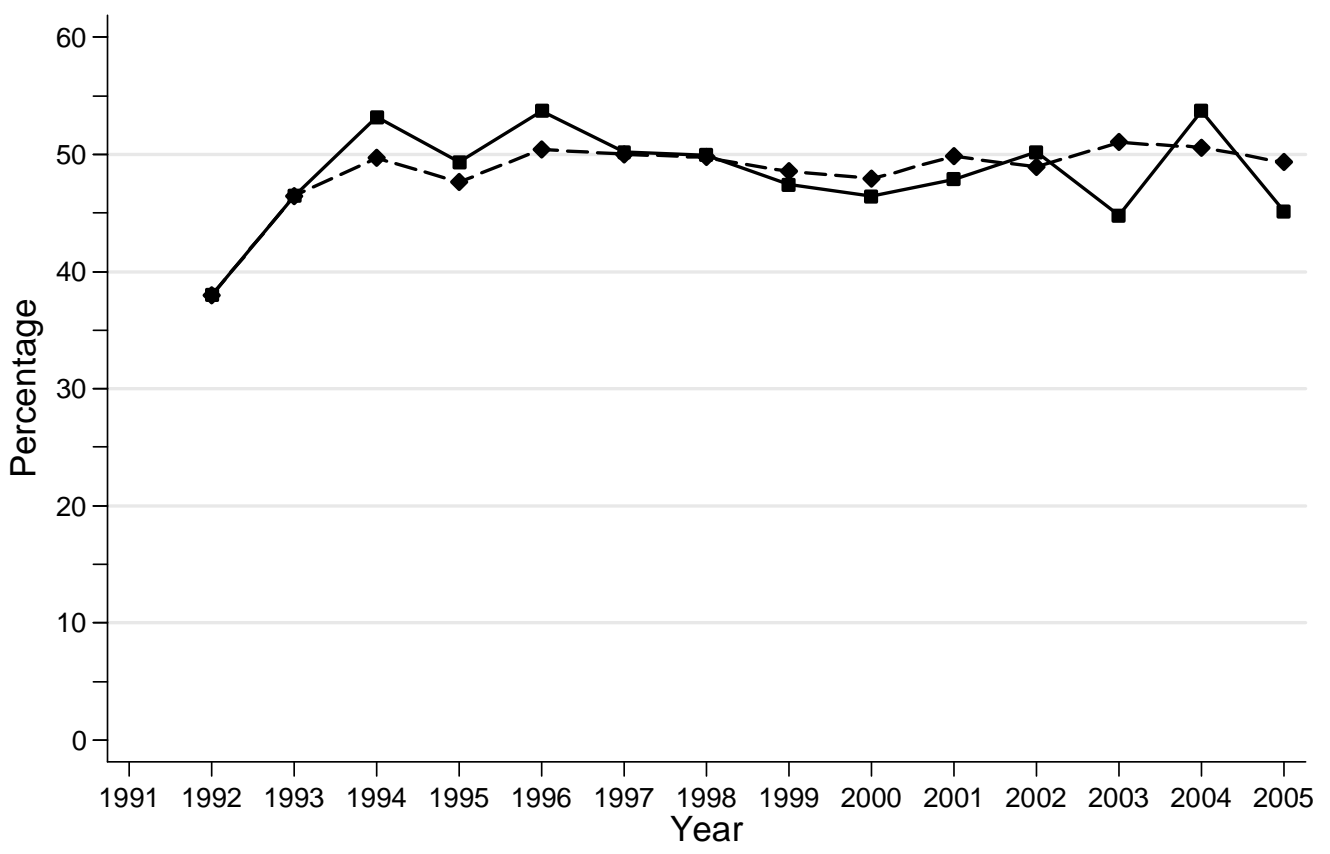

$\longrightarrow$ Exit rate, within-sample prediction

Note. Authors' calculations from BHPS data using parameter estimates shown in Table 3. The construction of the reference and counterfactual series is explained in the text. 
Figure 6. Counterfactual simulations of SA transition rates: what if the distribution of educational qualifications were to remain fixed at the 1991 distribution?

(a) Entry rates

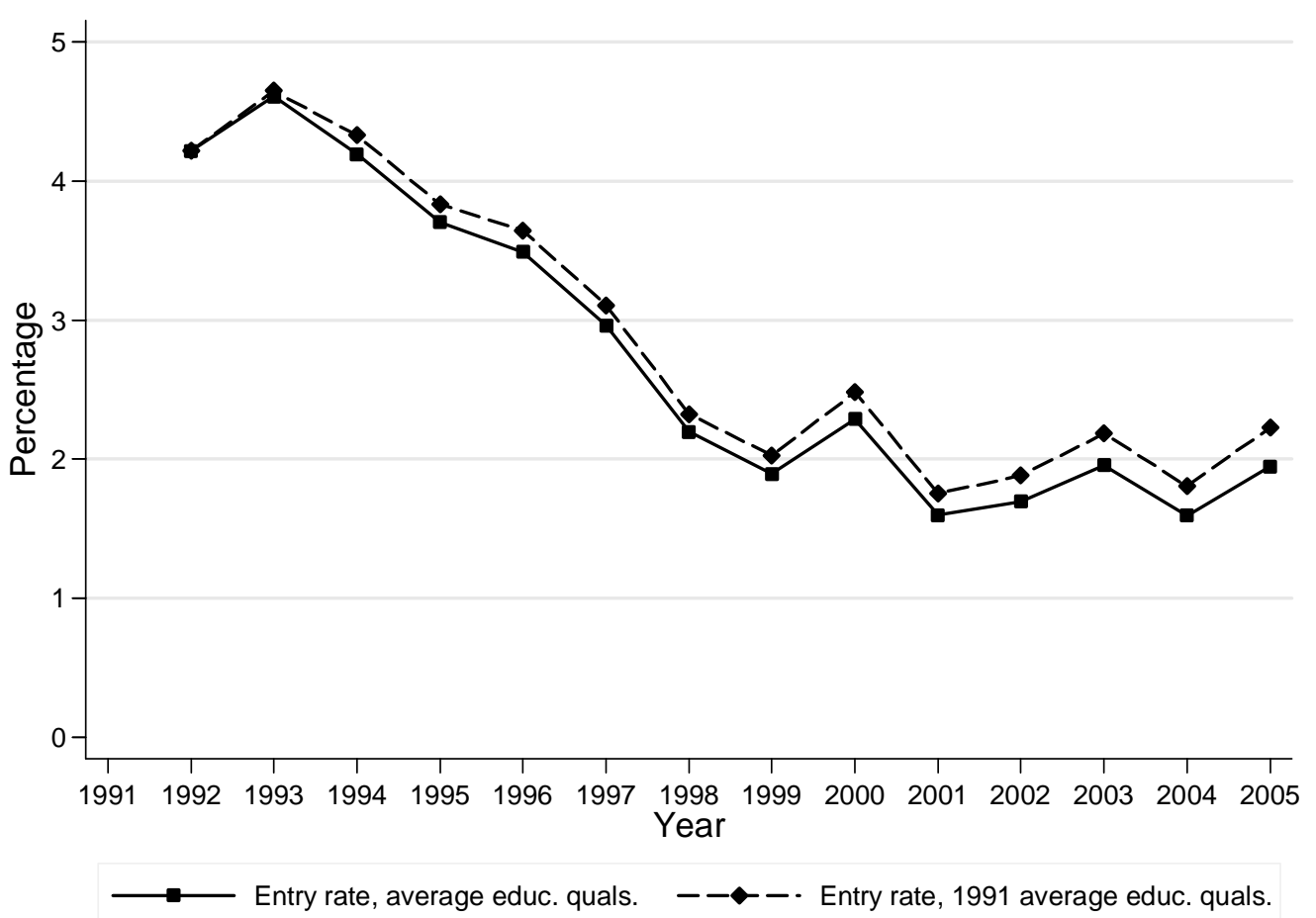

(b) Exit rates

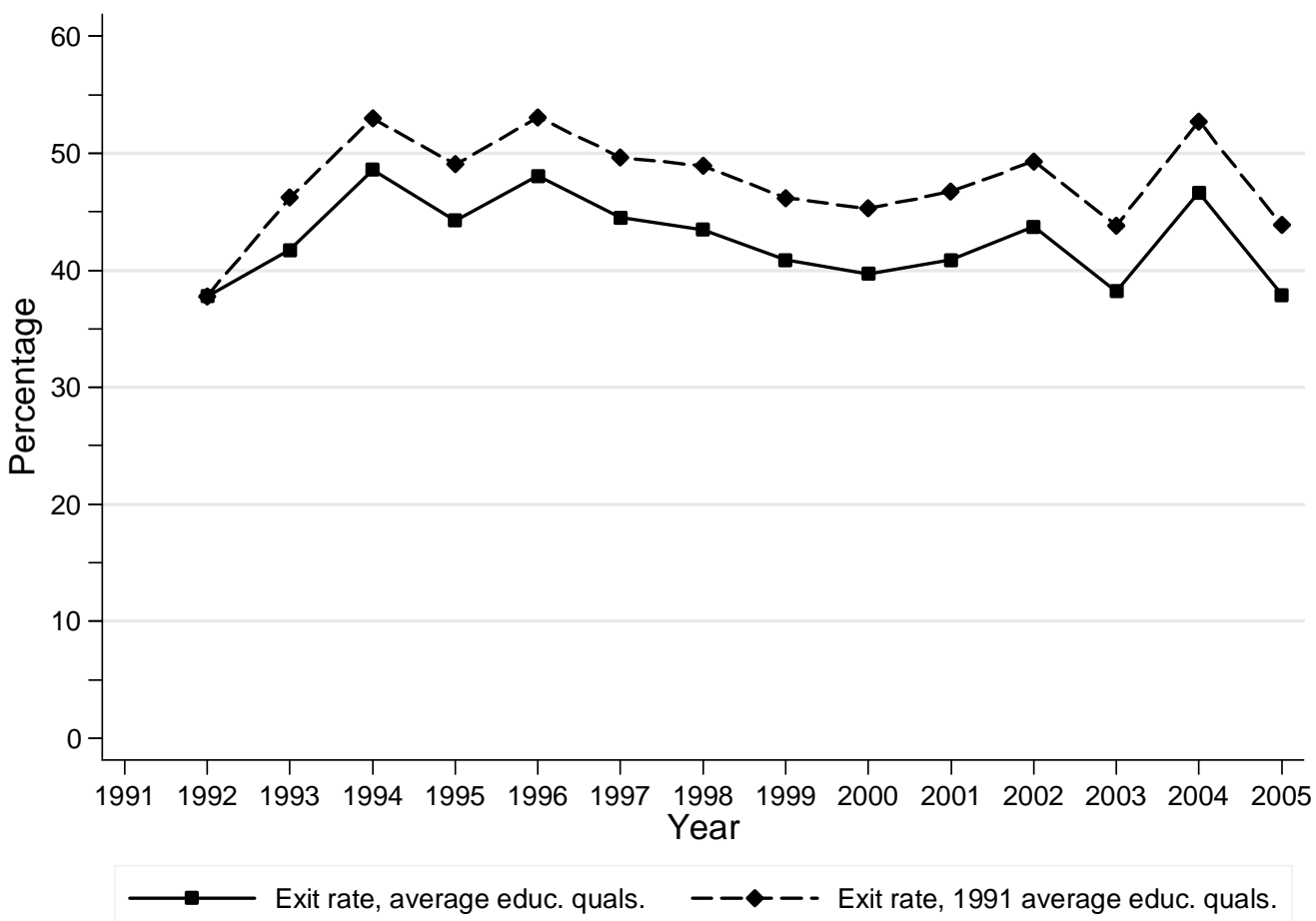

Note. Authors' calculations from BHPS data using parameter estimates shown in Table 3. The construction of the reference and counterfactual series is explained in the text. 